\title{
EXPANSÃO E CRISE NO MERCADO DE TRABALHO FORMAL FLUMINENSE ENTRE 1985 E 2019
}

\author{
Robson Santos Dias ${ }^{12}$ \\ ORCID: https://orcid.org/0000-0002-2157-2935 \\ Recebido em: 06/04/2021 \\ Publicado em: 30/06/2021
}

\begin{abstract}
RESUMO
Vários estudos vêm analisando os diferentes indicadores econômicos e apresentando suas conclusões sobre a dinâmica econômica e os gargalos estruturais da economia fluminense. Porém, um trabalho de atualização se faz sempre necessário, de modo a se avaliar as continuidades e descontinuidades na trajetória econômica regional, assim como se algumas das tendências indicadas em estudos mais antigos se confirmaram ou não. Nesse sentido, o objetivo do trabalho é analisar como evoluiu o mercado de trabalho formal fluminense entre 1985 e 2019, de modo a correlacionar com o principal do estado da arte sobre a economia fluminense e seus rebatimentos territoriais, e avaliar o impacto da crise a partir de 2015 nesse indicador que afeta diretamente no padrão de renda da população.
\end{abstract}

PALAVRAS-CHAVE: Mercado de trabalho formal; Estado do Rio de Janeiro; Municípios fluminenses.

\section{EXPANSION AND CRISIS IN THE FLUMINENSE FORMAL LABOR MARKET BETWEEN 1985 AND 2019}

\begin{abstract}
Several studies have analyzed the different economic indicators and presented their conclusions about the economic dynamics and structural bottlenecks of the Rio de Janeiro economy. However, an update is always necessary in order to evaluate the continuities and discontinuities in the regional economic trajectory, as well as if some of the trends indicated in older studies have been confirmed or not. In this sense, the objective of the work is to analyze how the formal labor market in Rio de Janeiro evolved between 1985 and 2019, in order to correlate it with the main state of the art on the Rio de Janeiro economy and its territorial rebatements, and to evaluate the impact of the crisis from 2015 on this indicator that directly affects the income pattern of the population.
\end{abstract}

KEYWORDS: Formal labor market; State of Rio de Janeiro; Municipalities of Rio de Janeiro.

\section{EXPANSIÓN Y CRISIS DEL MERCADO DE TRABAJO FORMAL FLUMINENO ENTRE 1985 Y 2019}

\footnotetext{
${ }^{1}$ Professor do Instituto Federal Fluminense - Campus Cabo Frio. Pesquisador do Núcleo de Estudos em Estratégia e Desenvolvimento (NEED-IFF) e do Observatório Socioeconômico dos Municípios Produtores de Petróleo (OBPETRO).

${ }^{2}$ A pesquisa contou com o suporte de Thobias Moraes Barreto (bolsista do programa Viva Ciência da Prefeitura de Campos dos Goytacazes) e André Reis Portes (bolsista do PIBIC-CNPq), ambos discentes da Licenciatura em Geografia do IFF-Campus Campos Centro.
} 


\section{RESUMEN}

Varios estudios han analizado los diferentes indicadores económicos y han presentado sus conclusiones sobre la dinámica económica y los cuellos de botella estructurales de la economía del estado de Río de Janeiro. Sin embargo, siempre es necesaria una actualización para evaluar las continuidades y discontinuidades en la trayectoria económica regional, así como si algunas de las tendencias indicadas en estudios más antiguos se confirmaron o no. En este sentido, el objetivo del trabajo es analizar cómo ha evolucionado el mercado de trabajo formal en el estado de Río de Janeiro entre 1985 y 2019, con el fin de correlacionarlo con el estado principal de la economía carioca y sus rebotes territoriales, y evaluar el impacto de la crisis a partir de 2015 en este indicador que afecta directamente al patrón de ingresos de la población.

PALABRAS CLAVE: Mercado laboral formal; Estado de Río de Janeiro; Municipios del Estado de Río de Janeiro.

\section{INTRODUÇÃO}

Dentre todos os indicadores da dinâmica econômica, sem dúvida aqueles ligados ao emprego possuem lugar central para a melhor avaliação do impacto das conjunturas e processos econômicos na vida concreta da população. O indicador mais popular, a variação do PIB, não possui essa correlação tão direta. Quantas vezes na história econômica brasileira (e fluminense) o crescimento do PIB teve poucos impactos reais na renda do trabalhador e no seu padrão de vida? No tocante ao emprego, a correlação é imediata: ganhos e perdas dos níveis de emprego afetam diretamente a vida da população, condicionando a renda das famílias e na própria dinâmica do mercado interno de consumo. Não obstante, a boa ciência ensina que para melhor apreender a complexa e mutável realidade social, econômica e territorial, é necessária a realização de correlações entre variáveis, de modo a permitir que nossa compreensão se aproxime do real.

Nesse sentido, o objetivo do trabalho é analisar como evoluiu o mercado de trabalho fluminense entre 1985 e 2019, de modo a correlacionar com o principal do estado da arte sobre a economia fluminense e seus rebatimentos territoriais, que vêm ganhando musculatura desde o fim da década de 1990. Vários desses estudos vêm analisando os diferentes indicadores econômicos e apresentando suas conclusões sobre a dinâmica econômica e seus gargalos estruturais. De certa maneira, o nosso estudo não traz novidades em relação a muito do que se escreveu sobre o Estado do Rio de Janeiro (ERJ). Porém, um trabalho de atualização se faz sempre necessário, de modo a se avaliar as continuidades e descontinuidades na trajetória econômica regional, assim como se algumas das tendências indicadas em estudos mais antigos se confirmaram ou não.

Até 2015, os estudos sobre a economia fluminense, mesmo os críticos, tratavam de compreender o significado da expansão ocorrida nos 15 ou 20 anos anteriores, dependendo da 
periodização de cada trabalho. Em 2015, entretanto, tudo virou de cabeça para baixo no Brasil e no ERJ em particular. Dali em diante, foram necessárias novas análises para compreender as mudanças e as novas tendências. Destarte, este estudo trata de analisar alguns dos impactos dessa mudança abrupta de perspectivas na economia fluminense no mercado de trabalho formal estadual e dos seus municípios.

No tocante à metodologia, recorremos à base de dados da Relação Anual de Informações Socias (RAIS) para a coleta dos dados brutos, a partir dos quais procedemos alguns cálculos aritméticos para apreender da melhor forma possível o movimento do mercado de trabalho ao longo do período. Alguns cálculos foram clássicos, como índices de evolução, crescimento percentual entre um período e outro e taxas de participação. Para além dessas abordagens bastante usuais, e buscando alcançar uma melhor medição do impacto do crescimento ou das perdas nos estoques de empregos formais, desenvolvemos um cálculo para mensurar o que chamamos de "influência no saldo". Explicando: a mensuração comum de crescimento entre um período e outro não leva em conta o tamanho do estoque prévio sobre o qual a taxa de crescimento percentual está incidindo. Um acréscimo $0,5 \%$ de empregos em Macaé tem um peso muito maior do que o crescimento de 10\% em Aperibé. Além disso, na formação do saldo final de um recorte com várias unidades, como o caso do ERJ e seus municípios, o seu saldo é composto pela soma e subtração de resultados positivos e negativos que vão formar o saldo que vai definir se o mercado de trabalho fluminense cresceu ou não. Então, por exemplo, ainda que todos os municípios fluminenses tenham expandido seus estoques, mas o município do Rio de Janeiro (MRJ) não, seu peso na formação do saldo final do estoque fluminense será determinante.

Assim, o cálculo que rotulamos de "influência no saldo" objetivou fazer essa mensuração: o saldo de cada município ao longo do período em análise e qual o "peso" de seu saldo na formação do estoque do estado. Esse peso pode ser positivo ou negativo. A notação matemática para esse cálculo está descrito abaixo:

$$
\mathrm{T}=\mathrm{G}+\mathrm{P}
$$

Sendo $\mathrm{T}$ (total de movimentação de formalidade), G (ganho de formalidade) e $\mathrm{P}$ (perda de formalidade). A partir desse cálculo, temos:

$$
\text { I_s }=\text { S_m / T }
$$

Sendo, I_s (impacto no saldo) e S_m (saldo municipal). 
Ou seja, primeiro calculamos todos os saldos positivos e negativos e com eles compomos um número da movimentação total dos ganhos e perdas de empregos formais ao longo do período analisado. Após, dividimos o saldo de cada município (S_m) pela soma da movimentação $(\mathrm{T})$. Daí conseguimos o resultado que precisávamos para mensurar a influência de cada município na formação do saldo final do estoque fluminense (ou do interior, ou da região metropolitana, conforme o caso $)^{3}$.

Ao longo do texto, pode ser observado que nem todos os dados que embasam a análise foram demonstrados nas tabelas e gráficos que estão dispostos ao longo do trabalho. Os cruzamentos que fizemos entre as informações dos microdados da RAIS foram numerosos e boa parte não pôde ser inserida ou seria demandada uma extensão muito maior de páginas ao artigo. Alguns desses dados suplementares foram melhor destrinchados no Boletim Técnico $\mathrm{n}^{\mathrm{o}} 1^{4}$, que embasou o trabalho.

Outro aspecto metodológico que foi adotado no trabalho foi sempre referenciar a dinâmica e evolução do mercado de trabalho formal fluminense com a média brasileira e com o conjunto dos demais estados. Isso foi particularmente importante para categorizar o desempenho bastante diverso dos 92 municípios fluminenses, no caso, se poderiam ser considerados mais ou menos dinâmicos em relação à média brasileira.

Por fim, o corpo principal do artigo está dividido em 4 partes. A primeira parte trata da evolução do emprego formal entre 1985 e 1999, enquanto que a segunda parte trata da evolução entre 2000 e 2014. Elas compõem o quadro pretérito do mercado de trabalho formal do estado, a partir do qual pode-se referenciar a dinâmica mais recente após 2014, que é o conteúdo tratado na terceira parte do artigo. Por fim, para melhor caracterizar como os dados analisados nas três primeiras partes evoluíram nos municípios fluminenses, a quarta parte sumariza os padrões espaciais derivados dos processos e expansão e retração da produção de emprego no estado, nesse caso, entre 2000 e 2019.

\section{O MERCADO DE TRABALHO FORMAL FLUMINENSE NAS DÉCADAS DE 1980 E 1990: CRISE E ESTAGNAÇÃO}

Em dezembro de 1990 e janeiro de 1991 ocorreram dois encontros reunindo intelectuais cariocas para tratar da crise fluminense (ou melhor dizendo, carioca). O título que

\footnotetext{
${ }^{3}$ Esse cálculo também foi realizado para a mensuração das variáveis setoriais e de salário, mas no caso substituindo o corte municipal pelo setor ou faixa salarial.

${ }^{4}$ https://obpetro.com.br/publicacoes/boletins-tecnicos/analise-da-evolucao-do-emprego-formal-no-estado-do-riode-janeiro-1992-2018/
} 
animava os debates expressava bem o espírito da época: "Rio de todas as crises" é bem verdade, do rescaldo do conturbado processo de redemocratização brasileira, que ocorreu em meio a um misto de sentimentos, entre as vitórias na institucionalização das responsabilidades sociais e democráticas do Estado brasileiro, e as incertezas causadas por políticas que não conseguiam debelar o fantasma da inflação.

O tema do esvaziamento econômico não era novo no discurso carioca. Desde pelo menos o final da década de 1950, nas vésperas da inauguração de Brasília, se reclamava de que o então Distrito Federal vinha perdendo indústrias para São Paulo, Minas Gerais e mesmo o antigo ERJ. No final da década de 1960 a Federação das Indústrias do Estado da Guanabara (FIEGA) patrocinou estudos que constataram certa estagnação carioca, enquanto que o ERJ, principalmente nos municípios da Baixada Fluminense, vinha se beneficiando do êxodo de empresas do território carioca (FIEGA, 1969). A partir desse diagnóstico buscaram criar um lobby junto aos militares em Brasília para realizar a fusão entre os estados da Guanabara e do Rio de Janeiro. Esta foi realizada, mais por motivos ligadas à visão territorial do II Plano Nacional de Desenvolvimento do que de qualquer demanda local. Entretanto, a justificativa da exposição de motivos da Lei Complementar $n^{0} 20$ de 1974 bebeu nesses estudos ao discorrer da unidade histórica, geográfica e econômica entre os dois estados.

Segundo verificou Silva (2004) posteriormente, não é possível dizer que houve de fato um esvaziamento econômico até 1980, nem do ERJ, nem da fração carioca. Ao contrário, houve significativa expansão liderada por investimentos estatais no território fluminense. Tal expansão, porém, teria sido menor que a de outros estados, levando a economia fluminense a perder participação relativa, mas não esvaziamento econômico.

No entanto, a partir da década de 1980, com a crise do modelo desenvolvimentista adotado no Brasil, os impactos foram profundos no ERJ. Deve-se ainda colocar nesse caldeirão os problemas não resolvidos da fusão, que foi executada com muitas promessas, mas poucas realizações. Essas dificuldades foram bastante realçadas ao longo do governo de Leonel Brizola, que não tinha receios de colocar na conta do governo federal a responsabilidade pelas dificuldades vividas no estado. Brizola foi sucedido pelo anódino governo de Moreira Franco, que passou sem deixar nenhuma marca em termos de políticas públicas, a não ser o sentimento de tempo perdido (DIAS, 2015). Ali de fato a economia fluminense tinha passado por perdas reais. Foi esse o contexto do "Rio de todas as crises". A

\footnotetext{
${ }^{5}$ O ensaio de análise econômica de Sulamis Dain (1990) se destaca entre os intervenientes do evento citado.
} 
síntese de um mal-estar generalizado sobre os rumos do estado numa época de incertezas quanto ao próprio país.

Até meados da década de 1990, a situação dominante foi a da crise, no ERJ e no Brasil. Uma nova fase se abriu com o do advento do Plano Real, que debelou a inflação, reduziu o papel indutor do Estado na economia e impôs reformas liberais que tiveram impacto direto no ERJ. Ainda que os problemas estruturais da economia fluminense não terem sido corrigidos, sendo talvez até aprofundados, tais eventos permitiram uma reversão de expectativas a respeito do crescimento econômico estadual. Não obstante, a década de 1990, após a profunda crise da década de 1980, foi marcada também pelo baixo crescimento, do Brasil e do ERJ.

Isso se refletiu no mercado de trabalho formal que entre 1985 e 1999 teve um crescimento de $25 \%$ do estoque agregado do país. O Rio de Janeiro foi de longe o estado que apresentou o pior resultado, de modo que foi o único que teve menos emprego que em 1985. Ao longo do período, o mercado de trabalho formal fluminense oscilou entre perdas e pequenas recuperações, caracterizando um quadro de estagnação da produção do emprego formal. Comparado aos mercados de trabalho de São Paulo e principalmente Minas Gerais, o ERJ foi a âncora baixista da tríade que forma o principal polo econômico do país.

Gráfico 1 - Índice de evolução do emprego - 1985-1999

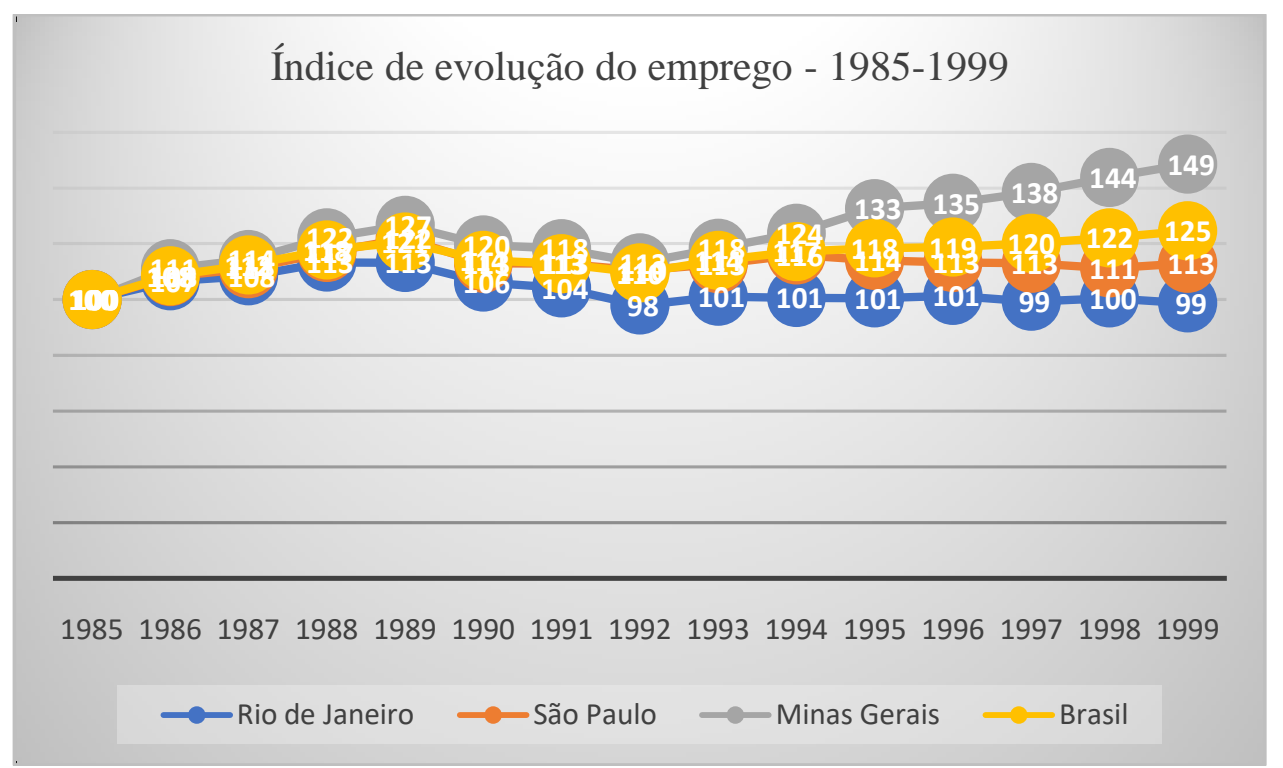

Fonte: RAIS (Relatório Anual Indicadores Sociais), MTE (Ministério do Trabalho e Emprego), http://pdet.mte.gov.br/microdados-rais-e-caged, 1985 (=100) - 1999. 
O setor que sofreu mais perdas no período foi a Indústria de Transformação, que influenciou com 40,7\% negativos na movimentação geral do emprego entre 1985-1999. As perdas fluminenses representaram $20 \%$ das perdas da indústria de transformação do país, atrás apenas de São Paulo devido ao maior peso deste estado. Em termos relativos, entretanto, a queda fluminense foi mais severa que a paulista ${ }^{6}$. O segundo setor mais atingido foi a administração pública, que pesou negativamente em $7,3 \%$ no saldo do período. Os outros setores que contribuíram para as perdas fluminenses foram a indústria extrativa mineral e os serviços industriais de utilidade pública. Por outro lado, os setores de serviços e comércio amenizaram as perdas ocorridas nos demais setores, apresentando influências positivas de $26,7 \%$ e $17,4 \%$ respectivamente. Resultados apenas o suficiente para manter o mercado de trabalho fluminense em relativa estagnação.

Tabela 1 - Evolução do emprego formal por setores 1985-1999

\begin{tabular}{|c|c|c|c|c|c|c|c|}
\hline & \multicolumn{2}{|c|}{ Estoque } & \multicolumn{2}{|c|}{ Índice } & \multicolumn{2}{|c|}{ Participação } & \multirow{2}{*}{$\begin{array}{c}\text { Influência no } \\
\text { saldo } \\
1985-1999\end{array}$} \\
\hline & 1985 & 1999 & 1985 & 1999 & 1985 & 1999 & \\
\hline Extrativa Mineral & 16.973 & 11.095 & 100 & 65,4 & $0,6 \%$ & $0,4 \%$ & $-1,1 \%$ \\
\hline Industria de Transformação & 520.334 & 306.019 & 100 & 58,8 & $19,5 \%$ & $1,6 \%$ & $-40,7 \%$ \\
\hline $\begin{array}{l}\text { Serviços Industriais de Utilidade } \\
\text { Pública }\end{array}$ & 49.573 & 43.032 & 100 & 86,8 & $1,90 \%$ & $1,6 \%$ & $-1,2 \%$ \\
\hline Construção Civil & 105.150 & 104.914 & 100 & 99,8 & $3,9 \%$ & $4,0 \%$ & $0,0 \%$ \\
\hline Comércio & 375.470 & 467.914 & 100 & 124,6 & $14,0 \%$ & $17,7 \%$ & $17,4 \%$ \\
\hline Serviços & 1.012 .225 & 1.152 .985 & 100 & 113,9 & $7,9 \%$ & $43,6 \%$ & $26,7 \%$ \\
\hline Administração Pública & 569.753 & 531.564 & 100 & 93,3 & $1,3 \%$ & $20,1 \%$ & $-7,3 \%$ \\
\hline $\begin{array}{l}\text { Agropecuária, Extração Vegetal, } \\
\text { Caça e Pesca }\end{array}$ & 9.544 & 24.076 & 100 & 252,3 & $0,4 \%$ & $0,9 \%$ & $2,8 \%$ \\
\hline Não Classificado & 14.841 & 408 & 100 & 2,7 & $0,6 \%$ & $0,0 \%$ & $-2,7 \%$ \\
\hline ERJ & 2.673 .863 & 2.642 .007 & 100 & 98,8 & & & \\
\hline
\end{tabular}

Fonte: RAIS (Relatório Anual Indicadores Sociais), MTE, http://pdet.mte.gov.br/microdados-rais-e-caged, $1985-1999$.

O impacto maior da crise e da posterior estagnação do mercado de trabalho formal fluminense se deu na base da pirâmide salarial, que sofreu perdas de $32 \%$ aproximadamente

\footnotetext{
${ }^{6}$ A indústria de transformação paulista influenciou negativamente em $70 \%$ do total setorial brasileiro, que também sofreu perdas severas. Entretanto, com relação ao estoque estadual, a indústria de transformação pesou negativamente na evolução do estoque em $30 \%$.
} 
ao longo do período. Por outro lado, nas demais faixas salariais ocorreu considerável incremento, apesar que esse resultado deve ser olhado com cautela, já que quase 40 mil postos de trabalhos não estavam classificados em nenhuma faixa salarial, fruto provavelmente de inconsistências na coleta de dados da RAIS. Não obstante, essa tendência foi nacional e o ERJ em todas as faixas salariais teve taxas de crescimento inferiores à média brasileira.

Tabela 2 - Faixas salariais médias 1985-1999

\begin{tabular}{llllllll}
\hline & Até 2 SM & 2 a 5 SM & 5 a 10 SM & 10 a 20 SM & \multicolumn{2}{l}{ Superior a 20 SM } & N Class. \\
\hline Estoque 1985 & 1.104 .622 & 911.522 & 357.334 & 175.920 & 75.635 & 48.830 \\
Estoque 1999 & 746.326 & 1.092 .849 & 477.617 & 196.645 & 118.863 & 8.998 \\
\hline Evolução 1985-1999 & $-32,4 \%$ & $19,9 \%$ & $33,7 \%$ & $11,8 \%$ & $57,2 \%$ & $-81,6 \%$ \\
\hline Participação no estoque 1985 & $41,3 \%$ & $34,1 \%$ & $13,4 \%$ & $6,6 \%$ & $2,8 \%$ & $1,8 \%$ \\
\hline Participação no estoque 1999 & $28,3 \%$ & $41,4 \%$ & $18,1 \%$ & $7,4 \%$ & $4,5 \%$ & $0,3 \%$ \\
\hline
\end{tabular}

Fonte: RAIS (Relatório Anual Indicadores Sociais), MTE, http://pdet.mte.gov.br/microdados-rais-e-caged, $1985-1999$.

Pode-se concluir que entre 1985 e 1999, no que tange ao mercado de trabalho formal, o ERJ oscilou entre perdas e a estagnação, com perdas severas principalmente na indústria de transformação, parcialmente contrabalançado pela expansão do comércio e dos serviços. Não se verificava ainda o impacto positivo das atividades petrolíferas no setor de extração mineral. Outro resultado digno de nota foi o impacto mais severo na base da pirâmide salarial. O ERJ foi, portanto, o mais afetado pela conjuntura de crise da economia brasileira, refletindo de forma mais profunda na perda de empregos formais e adentrando mais tardiamente na inflexão que se verificou na dinâmica do mercado de trabalho agregado do Brasil ${ }^{7}$.

\section{O MERCADO DE TRABALHO FORMAL FLUMINENSE ENTRE 2000 E 2014: A EUFORIA DA INFLEXÃO POSITIVA}

\footnotetext{
${ }^{7}$ Um dado que não utilizamos no artigo, mas que fez parte da pesquisa subjacente, é o que relaciona a PEA de 1991 e 2000 com o estoque de empregos da RAIS. Apesar da piora do seu quadro, o ERJ ainda se apresenta nessa variável numa condição privilegiada frente aos demais estados. Em 1991, o estoque de empregos formais representou $33 \%$ da PEA, terceira maior do país, mas caiu para $28 \%$ em 2000, a quarta naquele ano.
} 
A partir do final da década de 1990 novos pontos de vista começaram a despontar na literatura acadêmica fluminense. Após a situação bastante desfavorável do final da década de 1980 e início da década de 1990 (que inclusive impactou negativamente a dinâmica do emprego formal fluminense), a situação econômica do estado "deu uma melhorada" a partir de meados da década, embalada na euforia nacional com o fim da hiperinflação e seus efeitos imediatos no consumo. Começou-se a falar numa reversão da crise econômica fluminense, que passou a apresentar taxas de crescimento do PIB positivas. A Bacia de Campos se consolidava como província produtora de petróleo e gás e se via no horizonte perspectivas de novos investimentos impulsionados pela privatização das estatais e pela lei do petróleo de 1997. Começaram então a aparecer algumas das obras seminais analisando o que estava ocorrendo no ERJ. Temas como a análise do desempenho econômico então recente, a interiorização, a reestrutrução produtiva, a reestruturação da rede urbana e os impactos da economia do petróleo no desenvolvimento regional passaram a se tornar cada vez mais comuns.

Inicialmente, esse otimismo era mais virtual do que embasado em dados, como resposta ao pessimismo do início da década e evocando a euforia gerada pela implantação da agenda liberal e o salvacionismo do investimento privado estrangeiro. Uma característica comum dos textos analíticos entre fins dos anos de 1990 e primeiros anos da década de 2000 era apontar que esse otimismo se fundamentava em grande parte às promessas de novos investimentos, seja das multinacionais instaladas no estado a partir das privatizações, seja pelas perspectivas do mercado de petróleo, também aberto a investimentos privados, ou mesmo pelos primeiros resultados da inserção do governo estadual na guerra fiscal. Tal retomada, que de fato se confirmou mais tarde, era tão rudimentar que conclusões opostas foram tiradas em publicações cujo período em análise distava em dois ou três anos. Santos $(2003)^{8}$, por exemplo, buscando avaliar se o otimismo do final da década de 1990 tinha fundamento, verificou os indicadores do PIB fluminense entre 1985 e 1997 e concluiu que não haveria evidências que sustentassem a tese da superação da estagnação econômica. Conclusão que no tocante à produção de empregos formais, conforme viu-se acima, seria altamente defensável. Por outro lado, Natal (2005), analisando dados entre 1996 e 2000, já falava da possibilidade de considerar uma "inflexão positiva" na economia fluminense, expressão que se popularizou em análises posteriores. Esse autor, todavia, foi muito criterioso nessa definição, apontando que a expressão buscava uma analogia matemática indicando

\footnotetext{
${ }^{8}$ A análise original, um artigo que virou capítulo de livro da autora em 2003, foi publicada em 2000.
} 
“apenas que houve alguma reversão em relação à trajetória anterior, e não que a economia fluminense tenha experimentado qualquer tipo de crescimento econômico sustentado do tipo exponencial" (NATAL, 2005, p. 260, nota 27). De fato, ao se fazer uma leitura atenta do texto de Natal (2005) percebe-se que o autor se permite a considerar que o ERJ passava por mudanças importantes, porém não tanto a ponto de se concluir que o crescimento derivado dessas transformações fosse sustentado no tempo. ${ }^{9}$

Com efeito, a primeira década dos anos 2000 realmente representou uma mudança de trajetória, pelo menos na superfície. O ERJ acompanhou o bom momento econômico vivido pelo Brasil, mesmo enfrentando os efeitos da crise das hipotecas nos EUA a partir principalmente de 2009. No gráfico 2 verifica-se que a começar de 2000, o estoque de empregos formais teve uma expansão contínua em todo o Brasil até 2014, sem solução de continuidade a despeito da crise de 2008/2009. O ERJ seguiu a toada, entretanto num ritmo bem mais moderado que a média nacional, atingindo em 2004 um estoque 74\% maior que o ano base de 1985. Um crescimento considerável se comparado ao período anterior, no entanto, muito menor do que a média brasileira que cresceu $147 \%$ e mesmo Minas Gerais e São Paulo, $176 \%$ e 109\% respectivamente. Somente duas unidades federativas tiveram desempenho pior que o fluminense entre 2000 e 2014: Distrito Federal e Rio Grande do Sul.

Gráfico 2 - Evolução do emprego formal 2000-2014

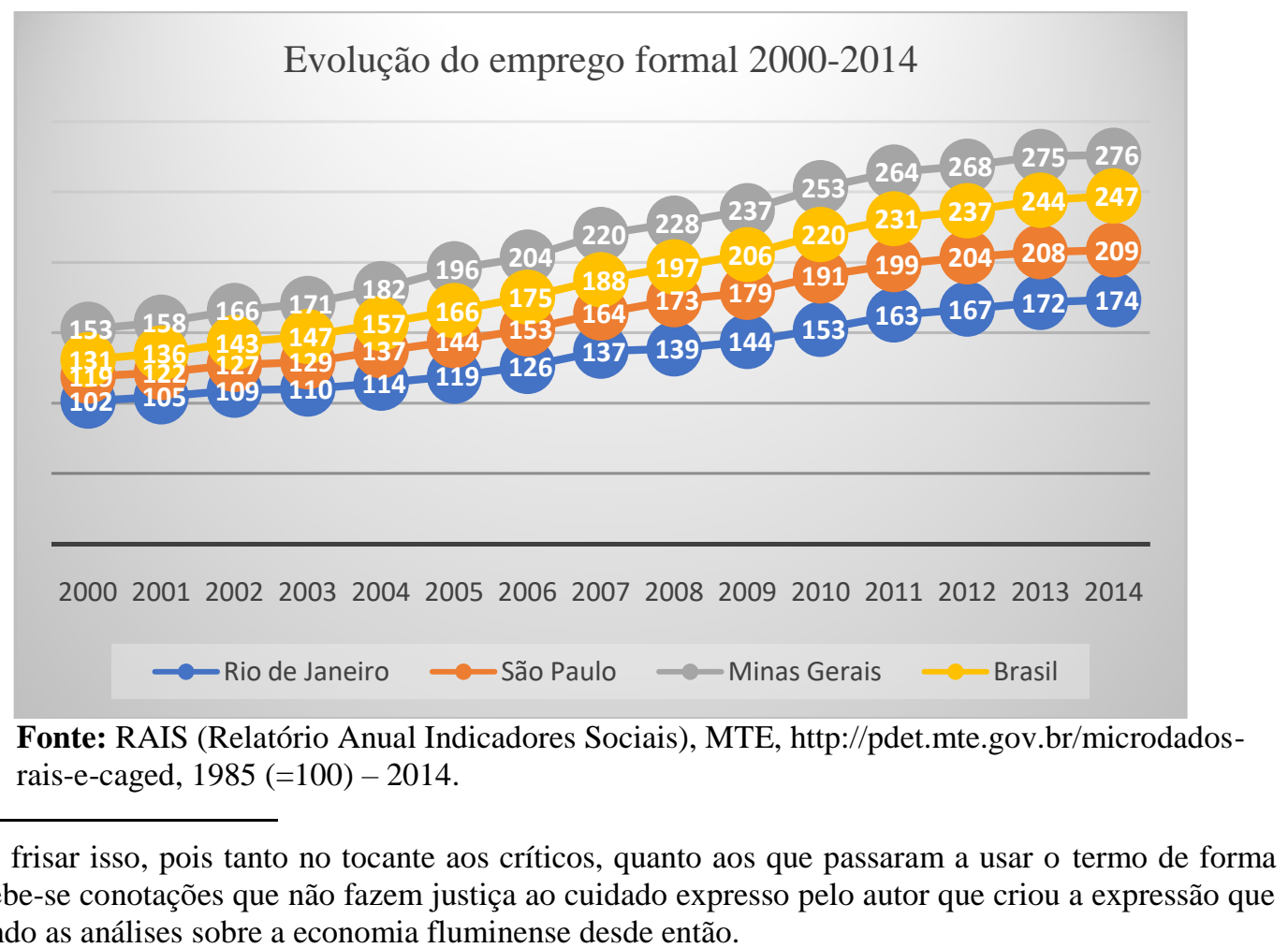

\footnotetext{
${ }^{9}$ É importante frisar isso, pois tanto no tocante aos críticos, quanto aos que passaram a usar o termo de forma eufórica, percebe-se conotações que não fazem justiça ao cuidado expresso pelo autor que criou a expressão que acabou marcando as análises sobre a economia fluminense desde então.
} 
A indústria extrativa mineral se destacou nesse período pelo extraordinário crescimento, principalmente se for considerado que entre 1985 e 1999 o setor apresentou perdas. Isto deve-se unicamente ao crescimento e consolidação das atividades de extração de petróleo e gás na Bacia de Campos, que teve seu auge no ínterim em análise e contribuiu com $92 \%$ da expansão setorial no período e teve participação de $82 \%$ do total das atividades extrativas no estado. Não obstante, trata-se de um setor com participação pequena no estoque total do emprego formal fluminense, apesar dos efeitos de encadeamento do setor serem deveras relevantes. ${ }^{10} \mathrm{~A}$ indústria de transformação conseguiu recuperar suas perdas em relação ao período 1985-1999, mas como seu ritmo de crescimento foi inferior à média estadual, continuou apresentando perda de participação. Como analisaram Silva (2012) e Sobral (2013) esse desempenho da indústria fluminense foi bastante desigual, já que foi basicamente impulsionado pela indústria automotiva na Região do Médio Paraíba, a indústria de produção de derivados de petróleo na Região Metropolitana e a Construção Naval, também impulsionada pelas compras da Petrobras. Por outro lado, setores tradicionais da indústria localizadas na Região Metropolitana, em particular no município do Rio de Janeiro, continuaram apresentando perdas relativas.

Depois da indústria extrativa mineral, o setor de construção civil foi o que apresentou melhor desempenho, de modo que cresceu mais do que a média brasileira para o setor. $\mathrm{O}$ setor de comércio também teve desempenho superior à média estadual, enquanto que os serviços ficaram próximos da média estadual, ambos, entretanto, abaixo da média brasileira para os setores. Cabe destacar que, dado o peso de seus estoques, os setores de comércio e, principalmente, serviços foram aqueles que mais contribuíram para a formação do saldo de estoque entre 2000 e 2014, com impacto de 21,3\% e 44\% respectivamente. Ao contrário do comércio, os serviços perderam um pouco de sua participação no estoque estadual. Os demais setores, serviços industriais de utilidade pública e administração pública cresceram abaixo da média estadual, perdendo com isso, participação. Apesar disso, a influência da administração pública no saldo do emprego continuou relevante.

\footnotetext{
${ }^{10}$ Como é sabido, o impacto das atividades petrolíferas em termos de impulso salarial, serviços sofisticados, impostos, PIB e, claro, dos royalties e participações especiais na economia fluminense foram imensos e já foram objeto de estudo de numerosas publicações.
} 
Tabela 3 - Evolução do emprego formal por setores 2000-2014

\begin{tabular}{|c|c|c|c|c|c|c|c|}
\hline & \multicolumn{2}{|c|}{ Estoque } & \multicolumn{2}{|c|}{ Índice } & \multicolumn{2}{|c|}{ Participação } & \multirow{2}{*}{$\begin{array}{l}\text { Influência no } \\
\text { saldo } \\
\text { 2000-2014 }\end{array}$} \\
\hline & 2000 & 2014 & 2000 & 2014 & 2000 & 2014 & \\
\hline Extrativa Mineral & 11.763 & 50.091 & 100 & 426 & $0,4 \%$ & $1,1 \%$ & $2,0 \%$ \\
\hline Industria de Transformação & 300.796 & 474.275 & 100 & 158 & $11,1 \%$ & $10,2 \%$ & $9,0 \%$ \\
\hline $\begin{array}{l}\text { Serviços Industriais de Utilidade } \\
\text { Pública }\end{array}$ & 40.290 & 58.873 & 100 & 146 & $1,5 \%$ & $1,3 \%$ & $1,0 \%$ \\
\hline Construção Civil & 102.092 & 301.354 & 100 & 295 & $3,8 \%$ & $6,5 \%$ & $10,4 \%$ \\
\hline Comércio & 482.415 & 891.489 & 100 & 185 & $17,7 \%$ & $19,2 \%$ & $21,3 \%$ \\
\hline Serviços & 1.213 .975 & 2.059 .563 & 100 & 170 & $44,7 \%$ & $44,4 \%$ & $44,0 \%$ \\
\hline Administração Pública & 543.073 & 780.804 & 100 & 144 & $20,0 \%$ & $16,8 \%$ & $12,4 \%$ \\
\hline $\begin{array}{l}\text { Agropecuária, Extração Vegetal, } \\
\text { Caça e Pesca }\end{array}$ & 23.508 & 24.931 & 100 & 106 & $0,9 \%$ & $0,5 \%$ & $0,1 \%$ \\
\hline Não Classificado & - & - & 100 & - & - & - & - \\
\hline ERJ & 2.718 .138 & 4.641 .380 & 100 & 171 & - & - & - \\
\hline
\end{tabular}

Fonte: RAIS (Relatório Anual Indicadores Sociais), MTE, http://pdet.mte.gov.br/microdados-rais-e-caged, anos $2000-2014$.

O expansionismo do emprego formal no período se deu pela ampla abertura de postos na base da pirâmide salarial, com enorme incremento dos postos até 2 salários mínimos, que passou a responder por metade dos empregos do estado, seguidos pelos postos entre 2 e 5 salários mínimos, que abocanhou um terço do estoque. Esses dois segmentos representaram em 2014 cerca de $80 \%$ do mercado de trabalho formal fluminense, seguindo a tendência nacional, que chegou em 2014 à condição de pleno emprego a partir do impulso da base da pirâmide $^{11}$. Por outro lado, observou-se perdas reais nas faixas mais altas da escala salarial, com o desempenho piorando conforme se sobe o nível salarial. Nesse quesito, o ERJ entrou na contramão da tendência nacional, principalmente se comparado com os estados com porte e perfil aproximados do Rio de Janeiro. Na faixa entre 5 e 10 salários mínimos o ERJ apresentou uma queda de $-1,1 \%$, pior que a média nacional, que apresentou um saldo positivo de $0,8 \%$. Não obstante, os desempenhos relativos foram aproximados. No entanto, na faixa

\footnotetext{
${ }^{11}$ Lembrando que se tornou popular na época o debate a respeito da emergência da chamada "classe c" ou "nova classe média", que incentivou estudos diversos com o objetivo de compreender tanto o que caracterizava essa "classe emergente", quanto para refinar com mais precisão o que seria, afinal, a classe média brasileira. Há de se notar, ainda, que esse boom de formalização de empregos na base da pirâmide foi potencializado pelos ganhos reais gerados pela política do governo federal de valorização do salário mínimo, que melhorou consideravelmente o poder de compra dos menores salários.
} 
entre 10 e 20 salários mínimos, que teve uma queda de $-6,8 \%$ no Brasil, teve um resultado positivo no ERJ, crescendo 7,3\%, que apesar de ter perdido participação no estoque estadual, contribuiu com $24 \%$ das contratações nessa faixa salarial no Brasil ao longo do período, inferior apenas ao Distrito Federal. Já na faixa superior a 20 salários mínimos, o ERJ apresentou uma queda importante de $-18,3 \%$, porém muito inferior à média nacional, que teve uma redução de $-36 \%$ de postos a partir dessa faixa salarial ${ }^{12}$.

Tabela 4 - Faixas salariais médias 2000-2014

\begin{tabular}{lcccccc}
\hline & Até 2 SM & 2 a 5 SM & 5 a 10 SM & 10 a 20 SM & Superior a 20 SM & N Class. \\
Estoque 2000 & 790.947 & 1.106 .093 & 490.153 & 205.030 & 116.667 & 9.248 \\
Estoque 2014 & 2.294 .183 & 1.463 .443 & 484.945 & 219.973 & 95.317 & 83.519 \\
Evolução 2000-2014 & $190,1 \%$ & $32,3 \%$ & $-1,1 \%$ & $7,3 \%$ & $-18,3 \%$ & $803,1 \%$ \\
\hline Participação no estoque 2000 & $29,1 \%$ & $40,7 \%$ & $18,0 \%$ & $7,5 \%$ & $4,3 \%$ & $0,3 \%$ \\
\hline Participação no estoque 2014 & $49,4 \%$ & $31,5 \%$ & $10,4 \%$ & $4,7 \%$ & $2,1 \%$ & $1,8 \%$ \\
\hline
\end{tabular}

Fonte: RAIS (Relatório Anual Indicadores Sociais), MTE, http://pdet.mte.gov.br/microdados-rais-e-caged, anos $2000-2014$.

Com efeito, o resultado relativamente positivo entre os postos salariais mais altos esteve diretamente ligado à expansão das atividades de petróleo e gás ${ }^{13}$, que responderam positivamente com um terço do saldo das contratações entre 2002 e 2014, compensando boa parte das perdas dessa faixa salarial que se deram principalmente em setores da administração pública e das atividades mais sofisticadas dos serviços, caso da intermediação financeira, dos serviços industriais de utilidade pública e de setores da indústria de transformação como a siderurgia e a indústria farmacêutica ${ }^{14}$.

\footnotetext{
${ }^{12}$ As razões para esse processo podem ser de diversas ordens. Ao analisar esses dados, duas hipóteses nos surgiram: a primeira, a de que esse processo resulta da primarização e perda de complexidade da estrutura produtiva brasileira. A segunda hipótese é de que tais reduções podem ter sofrido, em algum grau, um efeito estatístico devido a um possível descompasso entre os reajustes nominais dos maiores salários frente aos ganhos reais do salário mínimo nesse período.

${ }^{13} \mathrm{O}$ trabalho de Hasenclever, Mendes e Cavaliere (2016) realiza um detalhado estudo sobre a capacidade de encadeamento do setor de petróleo e gás no ERJ, assim como a qualidade do emprego gerado pela cadeia produtiva. A conclusão da investigação aponta que entre 2000 e 2010, pelo fato de ser um setor intensivo de capital, tem um índice multiplicador baixo em comparação com outros setores. Não obstante, ao longo do período houve uma notável expansão da capacidade indutora do setor na geração de empregos. Além disso, a cadeia produtiva se destaca pela maior participação dos empregos de alta escolaridade e altos salários na força de trabalho.

${ }^{14}$ Os dados considerados partiram de 2002 por razões de melhor tabulação do sistema da RAIS, que é mais completa a partir desse ano. Por esse motivo, alguns cruzamentos tornam-se impossíveis nos anos anteriores quando se necessita tabular um número maior de variáveis.
} 
Tabela 5 - Principais atividades com participação no estoque de empregos superiores a 10 SM - 2002-2014

\begin{tabular}{|c|c|c|c|c|}
\hline Atividades com evolução positiva & $\begin{array}{l}\text { Saldo } \\
2002- \\
2014\end{array}$ & $\begin{array}{l}\text { Influência no } \\
\text { saldo total }\end{array}$ & $\begin{array}{c}\% \text { no saldo } \\
\text { positivo }\end{array}$ & $\begin{array}{l}\text { PR estoque } \\
\text { 2014* }\end{array}$ \\
\hline Fabricação de produtos derivados do petróleo & 9.270 & $5,9 \%$ & $11,3 \%$ & $12,8 \%$ \\
\hline Extração de petróleo e gás natural & 8.537 & $5,4 \%$ & $10,4 \%$ & $12,9 \%$ \\
\hline $\begin{array}{l}\text { Atividades de serviços relacionados com a extração } \\
\text { de petróleo e gás exceto a prospecção realizada por } \\
\text { terceiros }\end{array}$ & 8.330 & $5,3 \%$ & $10,2 \%$ & $7,8 \%$ \\
\hline Atividades com evolução negativa & $\begin{array}{l}\text { Saldo } \\
2002- \\
2014\end{array}$ & $\begin{array}{l}\text { Influência no } \\
\text { saldo total }\end{array}$ & $\begin{array}{c}\text { \% no saldo } \\
\text { negativo }\end{array}$ & $\begin{array}{l}\text { PR estoque } \\
\quad 2014\end{array}$ \\
\hline $\begin{array}{l}\text { Administração do estado e da política econômica e } \\
\text { social }\end{array}$ & -6.004 & $-3,8 \%$ & $7,9 \%$ & $35,2 \%$ \\
\hline $\begin{array}{l}\text { Serviços coletivos prestados pela administração } \\
\text { pública }\end{array}$ & -6.448 & $-4,1 \%$ & $8,5 \%$ & $18,8 \%$ \\
\hline Intermediação monetária depósitos à vista & -9.430 & $-6,0 \%$ & $12,4 \%$ & $5,5 \%$ \\
\hline
\end{tabular}

Fonte: RAIS (Relatório Anual Indicadores Sociais), MTE, http://pdet.mte.gov.br/microdados-rais-e-caged, anos 2002 - 2014. Grupos de atividades CNAE 95

* Estoque dos empregos formais superiores a $10 \mathrm{SM}$

Concluindo, pode-se considerar que entre 2000 e 2014, o bom momento vivido, no geral, pela economia fluminense teve impactos bastante importantes no mercado de trabalho fluminense, que, é importante frisar, deveu-se a um movimento geral da economia brasileira de formalização do emprego, principalmente na base da pirâmide salarial. O ERJ foi, porém, um dos estados com menor ritmo de expansão do mercado de trabalho formal, que teve ainda a característica de se tornar cada vez mais especializado nas atividades de exploração e produção de petróleo e gás. Como aconteceu com o conjunto do país, os setores de serviços e comércio foram os principais impulsionadores do emprego, apesar da indústria de transformação ter tido uma sobrevida que, entretanto, não impediu a continuidade da perda de participação tanto no estoque estadual, quando no estoque brasileiro. Por outro lado, o ERJ foi um dos poucos estados, em especial considerando os estados de perfil e porte semelhantes ou superior (como São Paulo), que apresentou alguma compensação na perda de participação 
dos maiores salários, fenômeno em que os empregos gerados pela cadeia produtiva de petróleo e gás tiveram uma contribuição decisiva ${ }^{15}$.

\section{O ESPECTRO DO RIO DE TODAS AS CRISES ASSOMBRA NOVAMENTE: A CRISE A PARTIR DE 2015}

Como apontado anteriormente, a partir de meados da década de 1990, certo otimismo a respeito da economia fluminense passou a se difundir na imprensa e nos meios políticos e empresariais do estado, o que em geral quer dizer nos meios cariocas. A partir da formulação da expressão "inflexão econômica positiva" tal otimismo chegou, mesmo, a se configurar em certa euforia. A economia do petróleo ia de vento em popa ${ }^{16}$, garantindo polpudos recursos para os municípios do litoral norte do estado, assim como novos investimentos eram previstos a partir do impulso da Petrobras, das indústrias que se instalavam e com a confirmação da organização dos grandes eventos esportivos em 2007, 2014 e 2016. Na política, a aliança entre o PMDB fluminense e os governos do PT em Brasília anunciava que as antigas rusgas entre o governo do estado do Rio de Janeiro e o governo federal eram coisa do passado. $\mathrm{O}$ futuro era luminoso e os fantasmas do passado eram escondidos atrás dos biombos da então presumida prosperidade.

Não obstante, algumas vozes dissonantes se faziam ouvir através de investigações críticas a respeito das bases do expansionismo recente. A passagem da tese da "inflexão positiva" pelo crivo de análises mais detidas, aliás algo sugerido pelo trabalho seminal de Natal (2005), trouxe informações preocupantes sobre a solidez daquela fase de expansão econômica. Osório (2008) esboçara uma crítica à formulação da "inflexão positiva" ao apontar que entre 1995 e 2007 alguns indicadores econômicos da indústria apresentavam variações negativas, enquanto a média brasileira apresentou expansão, assim como o incremento de empregos formais tiveram no período expansão menor que a média nacional, como também apontamos aqui.

As conclusões de Sobral (2013) também foram pouco alvissareiras. Esse autor tem sido o principal crítico à tese da "inflexão positiva" ao ressaltar que, apesar da melhora de alguns indicadores, a economia fluminense e, em particular, metropolitana tem apresentado

\footnotetext{
15 Na relação entre emprego e PEA, entre 2000 e 2010 o ERJ recompôs as perdas da década anterior, apresentando um crescimento de $50 \%$ do estoque de empregos, enquanto a PEA cresceu $15 \%$. Isso possibilitou a melhora da participação do emprego formal na PEA, chegando a 36\% em 2010. Por outro lado, outros estados avançaram de forma mais veloz que o ERJ, que passou a ser apenas o sexto estado melhor posicionado nessa variável.

${ }^{16}$ Que teria novo impulso com a descobertas das jazidas no pré-sal, localizadas defronte ao litoral sul do estado a partir do pontal de Armação de Búzios.
} 
debilidades estruturais que têm se agudizado, refletindo, inclusive, as debilidades estruturais da economia brasileira desde a década de 1990. Apesar dos investimentos anunciados e concluídos, tanto nos setores encadeados pela extração de petróleo e gás, quanto na indústria de transformação (automobilística em particular), Sobral alertava para desarticulação do tecido produtivo do estado (e do país, em certa medida), que estaria se tornando cada vez mais "oco".

O descortinar da crise a partir de 2015 tornou gritante algumas dessas contradições. Os setores de petróleo e gás e de engenharia pesada, centrais para a economia fluminense,foram duramente atingidos pela confluência da baixa dos preços internacionais do petróleo, da destruição causada pela devassa da Lava Jato na Petrobras e nas empresas de engenharia pesada e da crise política derivada disso tudo. O ERJ acabou sendo o epicentro dessa crise ${ }^{17}$, de modo que a economia fluminense foi uma das mais afetadas pelo ensaio de depressão econômica seguida de estagnação até 2019.

Até 2014, a despeito da deterioração de outros índices econômicos, o Brasil caminhou até próximo do pleno emprego. A partir de 2015 houve uma severa reversão nesse processo, de modo que, com exceção de Roraima, houve perda de postos de trabalho em todas as unidades da federação no biênio 2015/16. O ERJ foi um dos mais impactados, com perdas totais de $10,4 \%$ dos empregos formais, apresentando perdas relativas inferiores apenas ao Amazonas. Para além desse fato, o ERJ se destacou negativamente nos anos de 2017 e 2018, período em que no agregado, o mercado de trabalho brasileiro estancou as perdas e ensaiou uma flutuação positiva, que, é importante dizer, não significa uma recuperação sólida. Em síntese, entre 2014 e 2016, o ERJ teve uma participação de 13,7\% das perdas de empregos do país, inferior apenas que São Paulo, enquanto que entre 2016 e 2019, quando o Brasil voltou a apresentar saldos discretamente positivos, o ERJ impactou negativamente em 5,7\% na evolução do estoque brasileiro. Somente o Distrito Federal teve uma contribuição absoluta pior que a fluminense.

\footnotetext{
${ }^{17}$ Não deixa de ser irônico, o fato de que políticos cariocas têm tido papel de destaque no processo de instabilização política que desembocou no impeachment de Dilma Roussef e no posterior desmonte de uma série de políticas e instituições centrais para o desenvolvimento nacional.
} 
Gráfico 3 - Evolução do emprego formal 2014-2019

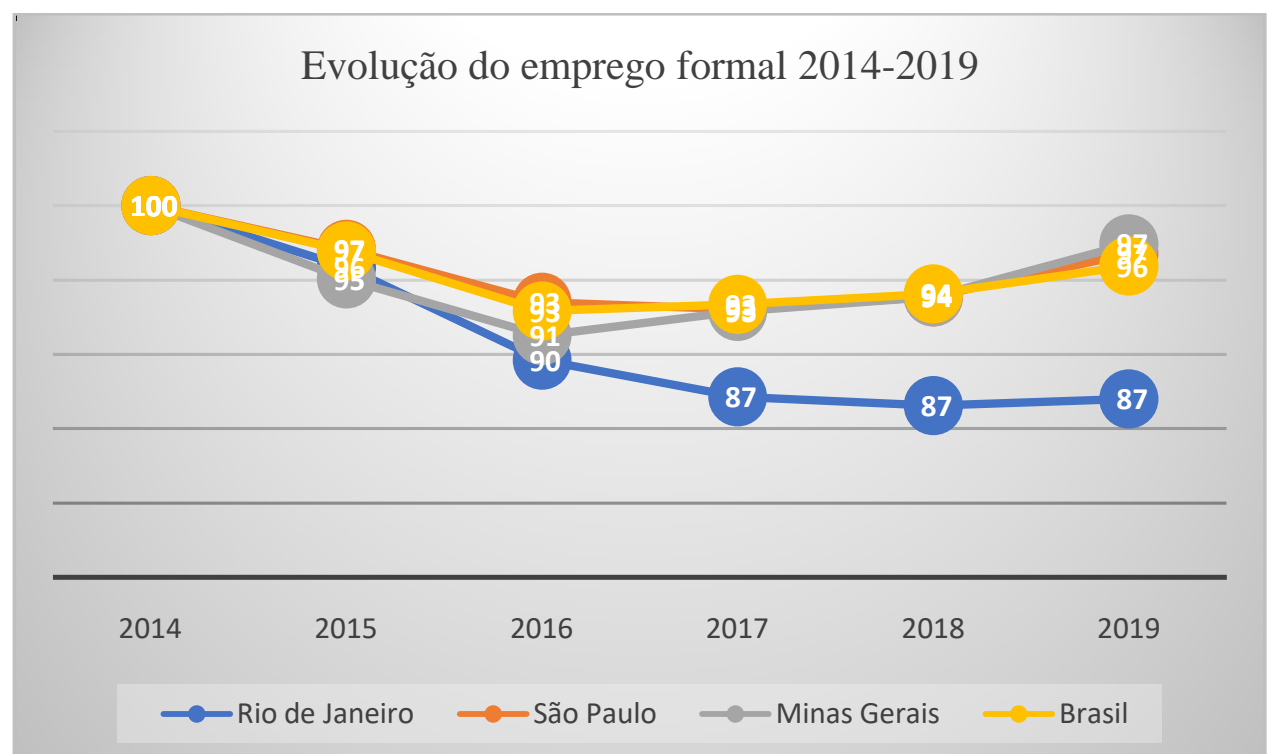

Fonte: RAIS (Relatório Anual Indicadores Sociais), MTE, http://pdet.mte.gov.br/microdadosrais-e-caged, anos 2014 (=100) - 2019.

Na tabela 6 se verifica que o ERJ, ao contrário de São Paulo e Minas Gerais e, evidente, do estoque total do Brasil, continuou sua trajetória de queda em 2017 e 2018, só estancando o processo de perdas em 2019, quando variou meio ponto percentual positivo. Verifica-se, portanto, que o ERJ, tal qual ocorrido nas décadas de 1980 e 1990, é um dos estados que reflete com maior intensidade e rapidez as crises que se instalam na economia brasileira, mas por outro lado, é um dos estados mais tardios na fase de estancamento de perdas e de retomada na produção de empregos.

Tabela 6 - Taxas de evolução percentual 2014-2019

2013-2014 2014-2015 2015-2016 2016-2017 2017-2018 2018-2019

$\begin{array}{lllllll}\text { Rio de Janeiro } & 1,2 \% & -4,1 \% & -6,5 \% & -2,8 \% & -0,7 \% & 0,5 \% \\ \text { São Paulo } & 0,6 \% & -2,9 \% & -3,7 \% & -0,5 \% & 0,9 \% & 3,1 \% \\ \text { Minas Gerais } & 0,3 \% & -4,9 \% & -4,0 \% & 1,8 \% & 1,1 \% & 3,8 \% \\ \text { Brasil } & 1,3 \% & -3,0 \% & -4,2 \% & 0,5 \% & 0,8 \% & 2,0 \%\end{array}$

Fonte: RAIS (Relatório Anual Indicadores Sociais), MTE, http://pdet.mte.gov.br/microdados-rais-e-caged, anos 2013 - 2019. 
Entre os setores, o que foi, de longe, o mais duramente atingido no ERJ foi a construção civil, que entre 2014 e 2016 perdeu quase $40 \%$ de seus empregos formalizados ${ }^{18}$, seguidos da indústria extrativa mineral e da indústria de transformação. Esses três setores foram responsáveis por $46 \%$ das perdas totais no mercado de trabalho formal fluminense. A indústria extrativa mineral (leia-se, petróleo), apesar do pequeno impacto de -2,6\% no saldo total do biênio, teve participação nas perdas duas vezes superior à sua participação no estoque de 2014, refletindo o impacto da crise internacional e da Lava Jato na indústria de petróleo do ERJ. A mesma inferência pode ser feita em relação à indústria de transformação (que tem na indústria naval um segmento importante que vinha sendo impulsionado pelas encomendas da Petrobras) e à construção civil. Nos setores de serviços e comércio o impacto da crise foi importante no estoque absoluto de empregos em razão do tamanho desses setores, porém percentualmente as perdas foram menos acentuadas. $\mathrm{O}$ mesmo pode ser dito a respeito da administração pública, que conta com o dispositivo da estabilidade como um elemento de suporte dos estoques e, por conseguinte, de amortecimento da crise, a despeito dos problemas fiscais que atingiram frontalmente os servidores públicos estaduais no período.

Entre 2016 e 2019 enquanto a indústria extrativa mineral conseguiu estancar as perdas ocorridas, a indústria de transformação e a construção civil não tiveram solução de continuidade na sua trajetória de queda do estoque de empregos. Os dois setores foram responsáveis por $30 \%$ das perdas no estado. Os setores de serviços e comércio também tiveram saldo negativo no período, porém a taxas percentuais bem menores, demonstrando que tendiam em 2019 para a estabilização e estancamento das perdas. A administração pública, por outro lado, apresentou uma flutuação positiva ao final de 2019, contribuindo em $4,5 \%$ na redução das perdas do estoque estadual.

\footnotetext{
18 É sabido que em 2014 e 2016 o município do Rio de Janeiro foi epicentro de obras para os grandes eventos esportivos. Seria natural que, após os eventos, os empregos na construção civil sofrerem uma baixa pela queda da demanda concentrada dos eventos, então é possível que, para além da crise, o resultado específico do setor tenha sofrido com esse fenômeno. Ao mesmo tempo, tendo em vista o impacto devastador da Lava Jato na engenharia pesada brasileira, que agravou ainda mais a situação econômica brasileira, tenha ocorrido a tempestade perfeita no setor. Um estudo mais detido seria necessário, mas foge ao escopo deste trabalho.
} 
Tabela 7 - Síntese da evolução do emprego formal por setores 2014-2019

\begin{tabular}{|c|c|c|c|c|c|c|c|c|c|c|c|}
\hline & \multicolumn{3}{|c|}{ Estoque } & \multicolumn{3}{|c|}{ Índice } & \multicolumn{3}{|c|}{ Participação } & \multicolumn{2}{|c|}{$\begin{array}{c}\text { Influência no } \\
\text { saldo }\end{array}$} \\
\hline & 2014 & 2016 & 2019 & 2014 & 2016 & 2019 & 2014 & 2016 & 2019 & $\begin{array}{l}2014- \\
2016\end{array}$ & $\begin{array}{l}2016- \\
2019\end{array}$ \\
\hline Extrativa Mineral & 50.091 & 37.477 & 37.434 & 100 & 75 & 75 & $1,1 \%$ & $0,90 \%$ & $0,9 \%$ & $-2,6 \%$ & $0,0 \%$ \\
\hline $\begin{array}{l}\text { Industria de } \\
\text { Transformação }\end{array}$ & 474.275 & 382.805 & 361.165 & 100 & 81 & 76 & $10,2 \%$ & $9,20 \%$ & $8,9 \%$ & $-19,0 \%$ & $-16,2 \%$ \\
\hline $\begin{array}{l}\text { Serviços Industriais } \\
\text { de Utilidade Pública }\end{array}$ & 58.873 & 56.390 & 56.478 & 100 & 96 & 96 & $1,3 \%$ & $1,40 \%$ & $1,4 \%$ & $-0,5 \%$ & $0,1 \%$ \\
\hline Construção Civil & 301.354 & 183.392 & 163.803 & 100 & 61 & 54 & $6,5 \%$ & $4,40 \%$ & $4,1 \%$ & $-24,5 \%$ & $-14,7 \%$ \\
\hline Comércio & 891.489 & 841.106 & 822.657 & 100 & 94 & 92 & $19,2 \%$ & $20,20 \%$ & $20,4 \%$ & $-10,5 \%$ & $-13,8 \%$ \\
\hline Serviços & 2.059 .563 & 1.901 .175 & 1.834 .615 & 100 & 92 & 89 & $44,4 \%$ & $45,70 \%$ & $45,4 \%$ & $-32,9 \%$ & $-49,9 \%$ \\
\hline $\begin{array}{l}\text { Administração } \\
\text { Pública }\end{array}$ & 780.804 & 733.853 & 739.884 & 100 & 94 & 95 & $16,8 \%$ & $17,60 \%$ & $18,3 \%$ & $-9,7 \%$ & $4,5 \%$ \\
\hline $\begin{array}{l}\text { Agropecuária, } \\
\text { ExtraçãoVegetal, } \\
\text { Caça e Pesca }\end{array}$ & 24.931 & 23.283 & 22.413 & 100 & 93 & 90 & $0,5 \%$ & $0,60 \%$ & $0,6 \%$ & $-0,3 \%$ & $-0,7 \%$ \\
\hline ERJ & 4.641 .380 & 4.159 .481 & 4.038 .449 & 100 & 90 & 87 & & & & & \\
\hline
\end{tabular}

Fonte: RAIS (Relatório Anual Indicadores Sociais), MTE, http://pdet.mte.gov.br/microdados-rais-e-caged, anos $2014-2019$.

No tocante aos perfis salariais, as principais novidades em relação ao período anterior foram as perdas na base da pirâmide salarial (até 5 SM), que tiveram forte expansão até 2014. Não obstante, as perdas do ERJ seguiram a tendência brasileira de impactar mais fortemente em termos relativos conforme o patamar salarial se eleva, porém em um declínio mais acentuado. Entre 2014 e 2016, as perdas foram significativamente menores em termos relativos nos postos que pagavam até $2 \mathrm{SM}$, piorando significativamente a partir dessa faixa. O impacto da crise foi particularmente forte entre os empregos superiores a 20SM, que perderam cerca de um quarto dos postos de trabalho no período. Para efeito de comparação, a média brasileira de perdas foi de $18 \%$. São Paulo e Minas Gerais se alinharam na média nacional. O Espírito Santo, que compartilha com o ERJ certa especialização nas atividades de extração de petróleo e gás teve um perfil de perdas bastante próximo ao caso fluminense, perdendo $25 \%$ dos empregos no topo da hierarquia e $16,7 \%$ entre 10 e 20 SM. Como 
resultado, a participação do ERJ nas perdas nas faixas salariais superiores a 10 SM no Brasil foram superiores a $20 \%$.

O ímpeto dessas perdas se desacelerou entre 2016 e 2019, porém comparada com a média nacional, que na base da pirâmide logrou alguma flutuação positiva, continuou a cair no ERJ. Cabe ainda destacar que no tocante à participação das faixas salariais, ocorreu a continuidade do processo de concentração dos postos de trabalho nas faixas salariais mais baixas. Não obstante, deve-se apontar que em 2019 o ERJ ainda possuía um percentual maior de empregos acima de 10 SM que a média brasileira, superior inclusive a São Paulo (4,6\% do estoque, contra $5,9 \%$ do ERJ).

Tabela 8 - Faixas salariais médias 2014-2019

\begin{tabular}{lcccccc}
\hline & Até 2 SM & 2 a 5 SM & 5 a 10 SM & 10 a 20 SM & Superior a 20 SM & N Class. \\
\hline Estoque 2014 & 2.294 .183 & 1.463 .443 & 484.945 & 219.973 & 95.317 & 83.519 \\
Estoque 2016 & 2.149 .321 & 1.251 .944 & 407.433 & 181.340 & 72.456 & 96.987 \\
Estoque 2019 & 2.033 .817 & 1.181 .205 & 397.865 & 169.496 & 66.973 & 189.093 \\
\hline Evolução 2014-2016 & $-6,3 \%$ & $-14,5 \%$ & $-16,0 \%$ & $-17,6 \%$ & $-24,0 \%$ & $16,1 \%$ \\
\hline Evolução 2016-2019 & $-5,4 \%$ & $-5,7 \%$ & $-2,3 \%$ & $-6,5 \%$ & $-7,6 \%$ & $95,0 \%$ \\
\hline Evolução 2014-2019 & $-11,3 \%$ & $-19,3 \%$ & $-18,0 \%$ & $-22,9 \%$ & $-29,7 \%$ & $126,4 \%$ \\
\hline Participação no estoque 2014 & $49,4 \%$ & $31,5 \%$ & $10,4 \%$ & $4,7 \%$ & $2,1 \%$ & $1,8 \%$ \\
\hline Participação no estoque 2016 & $51,7 \%$ & $30,1 \%$ & $9,8 \%$ & $4,4 \%$ & $1,7 \%$ & $2,3 \%$ \\
\hline Participação no estoque 2019 & $50,4 \%$ & $29,2 \%$ & $9,9 \%$ & $4,2 \%$ & $1,7 \%$ & $4,7 \%$ \\
\hline
\end{tabular}

Fonte: RAIS (Relatório Anual Indicadores Sociais), MTE, http://pdet.mte.gov.br/microdados-rais-e-caged, anos $2000-2014$.

$\mathrm{O}$ cruzamento entre as faixas salariais e as atividades econômicas traçam um quadro de grande complexidade, que caberia análises específicas para cada setor de atividade. Todavia, é possível traçar um panorama geral sobre como a evolução de ganhos e perdas nos postos de trabalho segundo os salários impactaram as atividades concretas. Como seria de se esperar, na base da pirâmide salarial as atividades dominantes são as ligadas ao setor de serviços e comércio. Com efeito, conforme se escala a pirâmide, a atividades que possuem maiores necessidades de especialização técnica são mais relevantes para a evolução geral da faixa salarial, ainda que sua participação no estoque total seja diminuta. Nesse caso, destaca- 
se o impacto negativo gerado pela crise no setor de petróleo que impôs perdas significativas nas atividades direta ou indiretamente ligadas à extração de petróleo e gás, que vai ganhando importância a partir das faixas superiores a 5 SM. Outro destaque é a importância dos empregos ligados ao setor público, seja o relacionado diretamente à administração pública, seja em atividades que têm no Estado um empregador fundamental, como o caso da educação infantil e fundamental. Verifica-se que o emprego público tem sido um importante sustentador do estoque de empregos nas faixas salariais baixas e médias, enquanto que nas faixas superiores verificou-se perdas bastante significativas ${ }^{19}$.

Tabela 9 - Desempenho das atividades econômicas entre 2014 e 2019

\begin{tabular}{|c|c|c|c|c|c|c|}
\hline $\begin{array}{l}\text { Faixa } \\
\text { salarial }\end{array}$ & $\begin{array}{l}\text { Desemp } \\
\text { enho }\end{array}$ & Atividade & Saldo & $\begin{array}{l}\text { Participação } \\
\text { estoque } \\
\text { faixa* }\end{array}$ & $\begin{array}{l}\text { Participação } \\
\text { no estoque* }\end{array}$ & $\begin{array}{l}\text { Influência no } \\
\text { saldo da faixa }\end{array}$ \\
\hline \multirow{6}{*}{ Até 2 sm } & \multirow{3}{*}{ Positivo } & $\begin{array}{l}\text { Comércio varejista não } \\
\text { especializado }\end{array}$ & 15.093 & $7,8 \%$ & $3,9 \%$ & $3,9 \%$ \\
\hline & & $\begin{array}{l}\text { Administração do estado e da } \\
\text { política econômica e social }\end{array}$ & 11.222 & $9,0 \%$ & $4,5 \%$ & $2,9 \%$ \\
\hline & & $\begin{array}{l}\text { Educação infantil e ensino } \\
\text { fundamental }\end{array}$ & 7.813 & $3,6 \%$ & $1,8 \%$ & $2,0 \%$ \\
\hline & \multirow{3}{*}{ Negativo } & $\begin{array}{l}\text { Comércio varejista de outros } \\
\text { produtos }\end{array}$ & -28.069 & $9,0 \%$ & $4,5 \%$ & $-7,3 \%$ \\
\hline & & $\begin{array}{l}\text { Construção de edifícios e obras de } \\
\text { engenharia civil }\end{array}$ & -29.507 & $1,8 \%$ & $0,9 \%$ & $-7,6 \%$ \\
\hline & & $\begin{array}{l}\text { Restaurantes e outros } \\
\text { estabelecimentos de serviços de } \\
\text { alimentação }\end{array}$ & -33.298 & $7,7 \%$ & $3,9 \%$ & $-8,6 \%$ \\
\hline \multirow{6}{*}{$\begin{array}{l}\text { Entre } 2 \\
\text { e } 5 \mathrm{sm}\end{array}$} & \multirow{3}{*}{ Positivo } & $\begin{array}{l}\text { Educação infantil e ensino } \\
\text { fundamental }\end{array}$ & 3.635 & $1,8 \%$ & $0,5 \%$ & $1,1 \%$ \\
\hline & & Telecomunicações & 2.482 & $0,9 \%$ & $0,3 \%$ & $0,8 \%$ \\
\hline & & Condomínios prediais & 1.926 & $4,7 \%$ & $1,4 \%$ & $0,6 \%$ \\
\hline & \multirow{3}{*}{ Negativo } & Outros transportes terrestres & -26.182 & $6,8 \%$ & $2,0 \%$ & $-8,0 \%$ \\
\hline & & $\begin{array}{l}\text { Administração do estado e da } \\
\text { política econômica e social }\end{array}$ & -29.895 & $21,7 \%$ & $6,4 \%$ & $-9,1 \%$ \\
\hline & & $\begin{array}{l}\text { Construção de edifícios e obras de } \\
\text { engenharia civil }\end{array}$ & -60.817 & $3,1 \%$ & $0,9 \%$ & $-18,6 \%$ \\
\hline Entre 5 & Positivo & Seguridade social & 1.035 & $0,4 \%$ & $0,0 \%$ & $1,2 \%$ \\
\hline
\end{tabular}

19 A hipótese possível de ser levantada é que essas perdas tenham ocorrido por motivos diversos, desde a aposentadoria de quadros do serviço público estimulada pelas reformas neoliberais que vêm sendo feitas a partir de 2016 no país, até o desligamento de quadros não estáveis, também consequência das restrições orçamentárias impostas nos últimos anos. 


\begin{tabular}{|c|c|c|c|c|c|c|}
\hline \multirow[t]{5}{*}{ e $10 \mathrm{sm}$} & & $\begin{array}{l}\text { Educação infantil e ensino } \\
\text { fundamental }\end{array}$ & 340 & $1,3 \%$ & $0,1 \%$ & $0,4 \%$ \\
\hline & & Telecomunicações & 268 & $1,7 \%$ & $0,2 \%$ & $0,3 \%$ \\
\hline & \multirow{3}{*}{ Negativo } & $\begin{array}{l}\text { Serviços coletivos prestados pela } \\
\text { administração pública }\end{array}$ & -5.101 & $10,3 \%$ & $1,0 \%$ & $-6,1 \%$ \\
\hline & & $\begin{array}{l}\text { Construção de edifícios e obras de } \\
\text { engenharia civil }\end{array}$ & -10.074 & $1,3 \%$ & $0,1 \%$ & $-12,1 \%$ \\
\hline & & $\begin{array}{l}\text { Administração do estado e da } \\
\text { política econômica e social }\end{array}$ & -19.537 & $34,5 \%$ & $3,4 \%$ & $-23,4 \%$ \\
\hline \multirow{6}{*}{$\begin{array}{l}\text { Entre } 10 \\
\text { e } 20 \mathrm{sm}\end{array}$} & \multirow{3}{*}{ Positivo } & $\begin{array}{l}\text { Pesquisa e desenvolvimento das } \\
\text { ciências físicas e naturais }\end{array}$ & 2.443 & $2,6 \%$ & $0,1 \%$ & $3,6 \%$ \\
\hline & & Transporte dutoviário & 1.090 & $1,0 \%$ & $0,0 \%$ & $1,6 \%$ \\
\hline & & $\begin{array}{l}\text { Outras atividades de } \\
\text { intermediação financeira, não } \\
\text { especificadas anteriormente }\end{array}$ & 904 & $0,7 \%$ & $0,0 \%$ & $1,3 \%$ \\
\hline & \multirow{3}{*}{ Negativo } & Atividades de atenção à saúde & -5.662 & $1,7 \%$ & $0,1 \%$ & $-8,4 \%$ \\
\hline & & $\begin{array}{l}\text { Construção de edifícios e obras de } \\
\text { engenharia civil }\end{array}$ & -6.136 & $0,7 \%$ & $0,0 \%$ & $-9,1 \%$ \\
\hline & & $\begin{array}{l}\text { Administração do estado e da } \\
\text { política econômica e social }\end{array}$ & -10.873 & $19,6 \%$ & $0,8 \%$ & $-16,1 \%$ \\
\hline \multirow{6}{*}{$\begin{array}{l}\text { Mais de } \\
20 \mathrm{sm}\end{array}$} & \multirow{3}{*}{ Positivo } & Transporte dutoviário & 739 & $1,4 \%$ & $0,0 \%$ & $2,2 \%$ \\
\hline & & $\begin{array}{l}\text { Outras atividades de } \\
\text { intermediação financeira, não } \\
\text { especificadas anteriormente }\end{array}$ & 507 & $1,0 \%$ & $0,0 \%$ & $1,5 \%$ \\
\hline & & $\begin{array}{l}\text { Intermediação não monetária } \\
\text { outros tipos de depósitos }\end{array}$ & 320 & $3,1 \%$ & $0,1 \%$ & $1,0 \%$ \\
\hline & \multirow{3}{*}{ Negativo } & $\begin{array}{l}\text { Construção de edifícios e obras de } \\
\text { engenharia civil }\end{array}$ & -2.500 & $0,6 \%$ & $0,0 \%$ & $-7,6 \%$ \\
\hline & & $\begin{array}{l}\text { Administração do estado e da } \\
\text { política econômica e social }\end{array}$ & -2.737 & $17,6 \%$ & $0,3 \%$ & $-8,3 \%$ \\
\hline & & Extração de petróleo e gás natural & -3.373 & $9,4 \%$ & $0,2 \%$ & $-10,2 \%$ \\
\hline
\end{tabular}

Fonte: RAIS (Relatório Anual Indicadores Sociais), MTE, http://pdet.mte.gov.br/microdados-rais-e-caged, anos 2014 - 2019. * Estoques de 2019

Conclui-se, portanto, que a crise que se instalou a partir de 2015 teve um impacto mais profundo no ERJ do que nas demais unidades da federação, confirmando, mais uma vez, um quadro estrutural da economia fluminense, que é o fato de que, enquanto nos ciclos expansionistas da economia brasileira o ERJ se apresenta como um retardatário, crescendo menos que a média nacional, durante as crises o impacto é mais profundo e duradouro. Entre 2016 e 2019, quando vários estados e mesmo o agregado brasileiro ensaiou uma pequena recuperação da perda de empregos, o ERJ continuou sua trajetória de queda, só começando a seguir o movimento nacional em 2019. 
Os setores mais atingidos foram aqueles ligados à indústria extrativa de petróleo e gás, incluindo setores encadeados na indústria de transformação, e setores ligados à construção civil. O impacto relativo maior foi também nas faixas salariais mais altas do mercado de trabalho, onde a participação desses setores é mais forte, que certamente gera efeitos na demanda de consumo da economia, impactando em cadeia os setores ligados ao comércio e aos serviços. Importante frisar o papel do serviço público na sustentação dos níveis de emprego formal e, por conseguinte, na demanda de consumo que ao fim permite a geração de renda e emprego em outros setores.

\section{ANÁLISE DOS PADRÕES ESPACIAIS DA EVOLUÇÃO DO MERCADO DE TRABALHO FORMAL FLUMINENSE}

O ERJ possui em sua geografia um clássico caso de macrocefalia urbana, a maior do Brasil. O centralismo urbano, político e econômico do município do Rio de Janeiro é derivado da herança de ter sido a mais importante cidade brasileira até meados do século XX. Com o esvaziamento econômico de amplas áreas do interior fluminense, a partir da crise da cafeicultura, ainda no início do século XX, esse centralismo tornou-se cada vez maior, na medida em que se intensificou a migração do antigo ERJ para o então Distrito Federal / Estado da Guanabara. Com exceção do Norte Fluminense, que logrou formar uma cidade de médio porte, Campos dos Goytacazes, e de alguns municípios das regiões do Médio Paraíba e Serrana que se industrializaram, o interior se caracterizou até o último quartel do século XX, pela presença de pequenas e estagnadas cidades.

Com a metropolização do Rio de Janeiro, formou-se a conhecida concentração de mais de $80 \%$ do PIB, da população e do mercado de trabalho na Região Metropolitana, dos quais pelo menos $60 \%$ se concentrava no território carioca. Essa situação começou a se reverter a partir de meados do século XX, quando se percebeu que as unidades fabris que se instalavam no território fluminense tendiam a preterir o MRJ em favor do antigo ERJ, em particular o entorno metropolitano ${ }^{20}$. O discurso do esvaziamento carioca costumava utilizar essas evidências empíricas para reclamar maior atenção federal para a situação da antiga capital federal ou mesmo para reivindicar a fusão.

No tocante ao mercado de trabalho formal, desde 1985 verifica-se um firme processo de desconcentração do emprego em benefício da periferia metropolitana e do interior

\footnotetext{
${ }^{20}$ Lembrando que a região metropolitana do Rio de Janeiro só foi oficialmente reconhecida em 1974, com a fusão entre os estados da Guanabara e do Rio de Janeiro.
} 
fluminense. Em 1985 a região metropolitana concentrava quase $88 \%$ dos empregos formais do estado, sendo que o o município do Rio de Janeiro sozinho concentrava 73\%. Em 2019, essa relação ficou em $77,8 \%$ na região metropolitana e $55,7 \%$ no município do Rio de Janeiro, de modo que independente de ter ocorrido expansão ou retração na produção de empregos formais, o MRJ tem perdido de forma consistente participação em relação ao restante da RMRJ e principalmente do interior.

Todavia, dada a magnitude da concentração do município do Rio de Janeiro no mercado de trabalho formal fluminense, sua dinâmica exerce um peso grande no desempenho estadual. Ao separar o município do Rio de Janeiro verifica-se que foram particularmente suas perdas que levaram o desempenho estadual para o negativo no período. Os municípios metropolitanos em conjunto e principalmente o interior tiveram resultados relativos bastante superiores à média estadual, de modo que se excluirmos a capital, o ERJ teria uma evolução relativa positiva, superior à média brasileira. ${ }^{21}$

Tabela 10 - Evolução do estoque de emprego por recortes e anos selecionados

\begin{tabular}{|c|c|c|c|c|c|c|}
\hline & & 1985 & 2000 & 2014 & 2016 & 2019 \\
\hline & RMRJ & 100 & 96 & 156 & 140 & 134 \\
\hline & Interior & 100 & 140 & 300 & 268 & 277 \\
\hline & MRJ & 100 & 89 & 136 & 122 & 115 \\
\hline & RMRJ (-MRJ) & 100 & 133 & 255 & 229 & 224 \\
\hline & ERJ (-MRJ) & 100 & 136 & 275 & 246 & 248 \\
\hline & ERJ & 100 & 102 & 174 & 156 & 151 \\
\hline & RMRJ & $87,9 \%$ & $83,3 \%$ & $79,1 \%$ & $79,2 \%$ & $77,8 \%$ \\
\hline & Interior & $12,1 \%$ & $16,7 \%$ & $20,9 \%$ & $20,8 \%$ & $22,2 \%$ \\
\hline & MRJ & $73,0 \%$ & $63,8 \%$ & $57,2 \%$ & $57,3 \%$ & $55,7 \%$ \\
\hline & RMRJ (-MRJ) & $14,9 \%$ & $19,5 \%$ & $21,9 \%$ & $21,9 \%$ & $22,1 \%$ \\
\hline & ERJ (-MRJ) & $27,0 \%$ & $36,2 \%$ & $42,8 \%$ & $42,7 \%$ & $44,3 \%$ \\
\hline & ERJ & - & - & - & - & - \\
\hline
\end{tabular}

Fonte: RAIS (Relatório Anual Indicadores Sociais), MTE, http://pdet.mte.gov.br/microdados-rais-ecaged, anos $1985-2019$.

\footnotetext{
${ }^{21}$ O Brasil apresentou índice de crescimento $(1985$ = 100) de 131 em 2000, 247 em 2014, 230 em 2016 e 237 em 2019. A partir de 2015, portanto, a RMRJ (-MRJ) passou a ter um desempenho abaixo da média brasileira, mas o interior após uma queda bastante intensa, teve uma retomada na produção de empregos mais forte que a média do país.
} 
A força gravitacional do mercado de trabalho carioca, que tem se caracterizado pelo menor dinamismo relativo (seja pela minoração das taxas de crescimento ou perdas em razão do seu tamanho, seja por razões estruturais), é o principal determinante da perda relativa de participação do ERJ no agregado brasileiro. No período entre 1985 e 1999, em que o ERJ apresentou um resultado negativo, foram em virtude do mal desempenho carioca, que impôs perdas de 53,4\% na movimentação do período. Por outro lado, o conjunto do ERJ, excluído o MRJ, teve um saldo positivo, ajudando a amenizar as perdas em $46,6 \%$.

Já no período expansivo entre 2000 e 2014 também pelo efeito do tamanho de seu mercado, o MRJ ajudou a amenizar a expansão mais acelerada que ocorria tanto nos municípios da periferia metropolitana, quanto do interior. Nota-se que a contribuição do MRJ de $47,9 \%$ foi significativamente inferior à sua participação no estoque de 2014 , que foi de $57,2 \%$. O interior conseguiu considerável avanço na produção de novos postos de trabalho, contribuindo com mais um quarto do saldo positivo do período, o que explica o apreciável avanço de sua participação de 16,7\% em 2000 para 20,9\% em 2014.

A crise a partir de 2015, por outro lado, atingiu duramente o conjunto do ERJ, já que a contribuição do MRJ, dos municípios da periferia metropolitana e do interior confluiu para suas respectivas participações no estoque estadual. O impacto setorial da crise na indústria extrativa (petróleo) e na indústria de transformação, que têm papel fundamental na expansão do interior e também nos municípios da periferia metropolitana, obviamente, foi o responsável pela confluência da queda entre 2014 e 2016. Entre este ano e 2019, porém, o interior fluminense, em seu conjunto esboçou alguma reação, enquanto que a RMRJ como um todo continuou na toada de perdas de postos de trabalho formais, impondo à dinâmica estadual uma influência negativa de $-83,3 \%$.

Tabela 11 - Influência na movimentação do mercado de trabalho

\begin{tabular}{lcccc}
\hline & $\mathbf{1 9 8 5 - 1 9 9 9}$ & $\mathbf{2 0 0 0 - 2 0 1 4}$ & $\mathbf{2 0 1 4 - 2 0 1 6}$ & $\mathbf{2 0 1 6 - 2 0 1 9}$ \\
RMRJ & $-56,5 \%$ & $73,1 \%$ & $-78,3 \%$ & $-83,3 \%$ \\
Interior & $43,5 \%$ & $26,9 \%$ & $-21,7 \%$ & $16,7 \%$ \\
MRJ & $-53,4 \%$ & $47,9 \%$ & $-56,6 \%$ & $-91,6 \%$ \\
ERJ (-MRJ) & $46,6 \%$ & $52,1 \%$ & $-43,4 \%$ & $8,4 \%$ \\
MRJ & $-69,3 \%$ & $65,5 \%$ & $-72,3 \%$ & $-88,0 \%$
\end{tabular}




\begin{tabular}{lllll} 
RMRJ (-RJ) & $30,7 \%$ & $34,5 \%$ & $-27,7 \%$ & $-12,0 \%$ \\
RMRJ (-RJ) & $50,8 \%$ & $48,3 \%$ & $-49,9 \%$ & $-37,5 \%$ \\
Interior & $49,2 \%$ & $51,7 \%$ & $-50,1 \%$ & $62,5 \%$ \\
\hline
\end{tabular}

Fonte: RAIS (Relatório Anual Indicadores Sociais), MTE,

http://pdet.mte.gov.br/microdados-rais-e-caged, anos 1985 - 2019.

A dinâmica espacial desse processo foi alvo de um número considerável de estudos, principalmente a partir do final da década de 1990. O fenômeno da desconcentração econômica, principalmente industrial, para os municípios fronteiriços ao Rio de Janeiro era um fenômeno já conhecido desde, pelo menos, a década de 1960. Já o fenômeno do crescimento econômico e populacional do interior passou a ser discutido com maior frequência a partir de meados da década de 1990. O trabalho de Limonad (1996) teve o mérito de ser pioneiro em realizar uma análise global da urbanização do interior fluminense, dado o interesse quase exclusivo com o município do Rio de Janeiro ou no máximo a região metropolitana, salvo alguns estudos parciais que se voltavam para o interior ${ }^{22}$.

A partir do processo de desconcentração em curso, pelo menos, desde a década de 1980 em direção ao interior, aumentou o interesse por compreender o fenômeno. O advento, principalmente, da exploração de petróleo e gás na Bacia de Campos, mas também a reestruturação da indústria no Médio Paraíba fez surgir uma outra tese, a par com a "inflexão positiva", no caso, a interiorização da economia fluminense. O trabalho mais destacado sobre o tema foi o de Oliveira (2003) que apresentou uma análise das mudanças ocorridas a partir da década de 1990, apontando os processos de reestruturação produtiva como o motor da reestruturação do território fluminense. Nesse sentido, estariam sendo criadas novas regionalizações econômicas baseadas em setores novos, menos dependentes do núcleo metropolitano, ainda que fortemente conectados com a capacidade de gestão e serviços existentes no MRJ.

Mesmo na RMRJ, novos impulsos industrializantes ocorreram desde o final da década de 1990, em particular na faixa oeste (Seropédica, Itaguaí, Japeri, Queimados e Paracambi), onde vem se instalando um complexo logístico-industrial-portuário importante, e na faixa leste (Magé, Guapimirim, São Gonçalo, Itaboraí, Tanguá, Rio Bonito e Maricá),

\footnotetext{
${ }^{22}$ Houve, é claro, estudos sobre o interior fluminense antes do trabalho de Limonad (1996), mas além de serem, em geral, parciais, como afirma a própria autora, foram muito espaçados no tempo. A obra seminal de Alberto Ribeiro Lamego datava da primeira metade do século XX. Em 1983, a FAPERJ publicou um estudo intitulado "Urbanização do interior fluminense: análise dos aglomerados de pequeno porte", fruto de pesquisa coordenada por Lysia Bernardes.
} 
impulsionada pela construção do COMPERJ ${ }^{23}$. Segundo Oliveira (2015), a partir da industrialização dessas áreas da periferia metropolitana, estariam se formando maiores interdependências com os eixos de dinamismo tanto do Médio Paraíba quanto do Norte Fluminense/Baixadas Litorâneas (ver o cinturão de crescimento do mercado de trabalho no Figura 1).

Fany Davidovich (2001) observa que o processo de metropolização fluminense se deu, desde a industrialização induzida por investimentos estatais, pela formação de eixos de transporte que permitiam a separação entre as sedes corporativas no Rio de Janeiro e as unidades fabris no interior fluminense. Com efeito, Davidovich identificou a existência de quatro eixos a partir do MRJ, integrando o Médio Paraíba, o eixo de Três Rios/Juiz de Fora, o litoral sul (Angra dos Reis) e o litoral norte (Baixada Litorânea). Mais tarde Davidovich (2010) refinando a análise dos eixos, questiona a precisão da definição tradicional de rede de cidades, baseada nas centralidades christallerianas, para falar de um processo de metropolização descontínua tendo como referência a distância de duas horas e meia do núcleo metropolitano pelas rodovias que formam esses eixos.

Lencioni (2015) avança na análise desse fenômeno, atualizando o conceito de megalópole para o conceito de megarregião entre São Paulo e Rio de Janeiro, para descrever o processo de urbanização difusa e polinucleada a nível regional, que no território fluminense incluiria cerca de cinquenta municípios. Lencioni é cuidadosa ao estabelecer o limite norte da megarregião a Cabo Frio, apesar de considerar existir a tendência de inclusão de Macaé e Campos dos Goytacazes nesse recorte. Na nossa avaliação, isso não seria tendência, mas um fato já consolidado, principalmente no que tange a Macaé.

O mapeamento da dinâmica geral do emprego no ERJ confirma tais análises, inclusive coincidindo, no essencial, com o desenho do mapeamento de Davidovich (2010). No período expansivo entre 2000 e $2014^{24}$ observa-se que, a partir do MRJ estruturaram-se dois eixos litorâneos para o norte e para o sul de dinamismo do mercado de trabalho. Em azul no Mapa 1 estão os municípios que cresceram mais do que a média brasileira no período, que foi de 89\%. Alguns municípios tiveram expansão relativa deveras acelerada, como o caso de Rio das Ostras, que cresceu 727\%, Porto Real 520\% e Saquarema 467\%. No caso de Rio das Ostras, o crescimento foi vigoroso o suficiente para elevar o patamar do município de um

\footnotetext{
${ }^{23}$ Moraes e Santos (2019) demonstram que entre 2006 e 2016, a maior parte dos investimentos na indústria de transformação no estado ainda se dirigem para a região metropolitana e, em menor grau, para a região do Médio Paraíba Fluminense.

${ }^{24}$ Em razão da necessidade de economicidade de espaço, optou-se por iniciar a análise espacial da dinâmica de emprego fluminense na fase expansiva a partir de 2000. Com isso, ao contrário da periodização adotada ao longo do artigo, não incluímos o período entre 1985 e 1999.
} 
pequeno mercado de 3767 empregos formais em 2000 para um respeitável estoque de 31150 empregos em 2014, de modo a passar a pertencer ao rol de municípios fluminenses com mercados de trabalho superiores a 20 mil empregados formais.

O padrão de crescimento relativo do emprego, entretanto, não permite avaliar o impacto do ganho ou perda de empregos em decorrência da força gravitacional do estoque municipal. Daí destacamos no mapa em pontilhado os municípios selecionados como estoques grandes, com maior capacidade de influenciar no saldo absoluto da dinâmica do emprego, no caso, municípios com estoques superiores a 20 mil empregos formais em 2014. Ao todo, 22 municípios entram nesse rol, representando em 2014 89\% do estoque fluminense (sendo $57 \%$ só o MRJ), incluindo, em sua maioria as cidades médias fluminenses. Alguns desses municípios estão entre os que apresentaram crescimento superior à média brasileira, no caso, Macaé, Campos dos Goytacazes, Itaperuna, Cabo Frio, Saquarema, Itaboraí, Duque de Caxias, São João de Meriti, Itaguaí e Angra dos Reis, abocanhando 27,6\% dos empregos fluminenses, exceto MRJ. É trivial apontar que a maior parte desses municípios foram impulsionados pelos investimentos na indústria do petróleo, seja no segmento upstream seja no downstream, seja em atividades da indústria de transformação ligadas à cadeia produtiva do petróleo, como o caso da indústria naval em Angra dos Reis. Macaé teve uma participação destacada por abocanhar mais de $20 \%$ dos empregos gerados no interior ao longo do período. Alguns outros municípios apresentaram uma expansão mais modesta, mas superior à média estadual, caso de Resende, Niterói, São Gonçalo e Teresópolis, enquanto que os industrializados municípios de Volta Redonda, Barra Mansa, Nova Friburgo, Petrópolis, Nova Iguaçu e, obviamente, o Rio de Janeiro, tiveram taxas de expansão abaixo da média estadual. 
Figura 1- Evolução do emprego formal entre 2000 e 2014

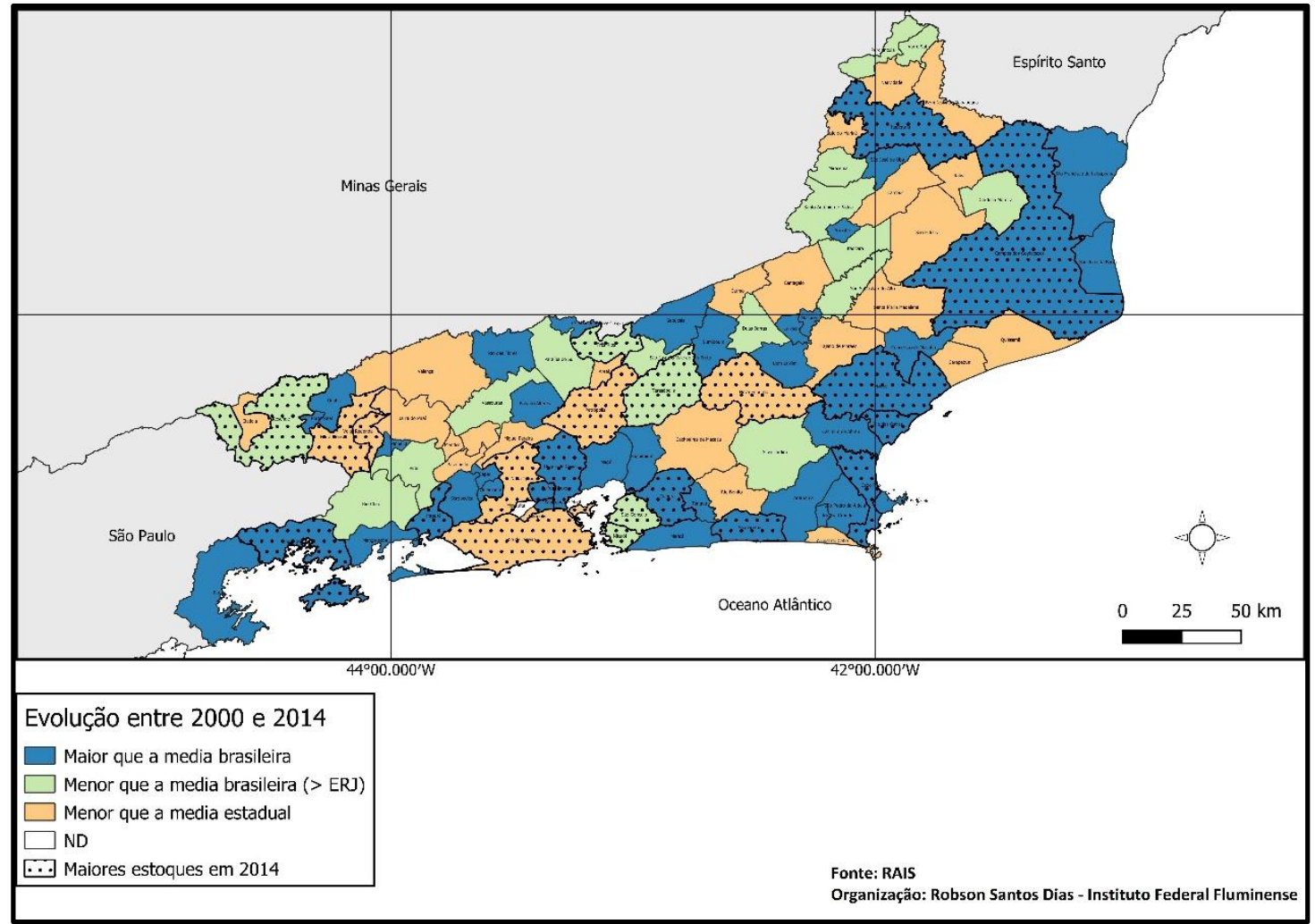

Fonte: RAIS (Relatório Anual Indicadores Sociais), MTE, http://pdet.mte.gov.br/microdados-rais-ecaged, anos 2000 - 2014, elaboração do autor (Instituto Federal Fluminense)

A crise que se abateu no país foi particularmente profunda justamente nos mesmos eixos de dinamismo do período expansivo, que ou decaíram mais que a média brasileira, que foi negativa no período (-7\%), ou mesmo que a média estadual (-10\%). Os municípios mais atingidos foram aqueles cuja prosperidade anterior dependeu fundamentalmente da expansão das atividades petrolíferas ${ }^{25}$. Os municípios mais afetados por essas atividades, no caso, Macaé, Campos dos Goytacazes, Rio das Ostras, Itaboraí, Duque de Caxias e Angra dos Reis tiveram 40,7\% das perdas fluminenses, excluído o MRJ. Dos principais municípios, apenas Cabo Frio não apresentou perdas entre 2014 e 2016, possivelmente em razão da reorientação

\footnotetext{
${ }^{25}$ Em relação aos municípios que foram impulsionados pelo desenvolvimento das atividades da cadeia produtiva de petróleo e gás natural, é importante destacar a segmentação dos municípios em dois grupos: aqueles que sediam as estruturas produtivas da "economia do petróleo" e aqueles municípios que se tornaram meramente "petrorrentistas", ou seja, foram impulsionados pelas rendas oriundas dos royalties e participações especiais, auferidas por lei (PESSANHA, 2015). Com efeito, é trivial dizer que a abrupta crise setorial iniciada em 2015 teve impactos profundos tantos nos municípios partícipes da economia do petróleo, quanto nos municípios petrorrentistas. No entanto, os últimos se encontraram em situação de maior fragilidade, em virtude da vulnerabilidade fiscal de seus municípios. Dentre os municípios confrontantes à Bacia de Campos, pode-se comparar a situação dos dois principais municípios da região, Campos dos Goytacazes e Macaé. Ambos tiveram perdas severas de empregos formais a partir de 2015, porém Campos dos Goytacazes, majoritariamente petrorrentista, tem se defrontado com grave problema fiscal, enquanto Macaé conseguiu manter o equilíbrio de suas contas. O município foi capaz de amortecer a queda da renda petrolífera com os impostos municipais pagos pela Petrobras e suas terceirizadas.
} 
dos fluxos de turismo causada pela crise econômica ${ }^{26}$. O impacto no cinturão da indústria de transformação do Médio Paraíba foi também severo, seguindo a tendência nacional de deterioração do emprego industrial.

Figura 2 - Evolução do emprego formal entre 2014 e 2016

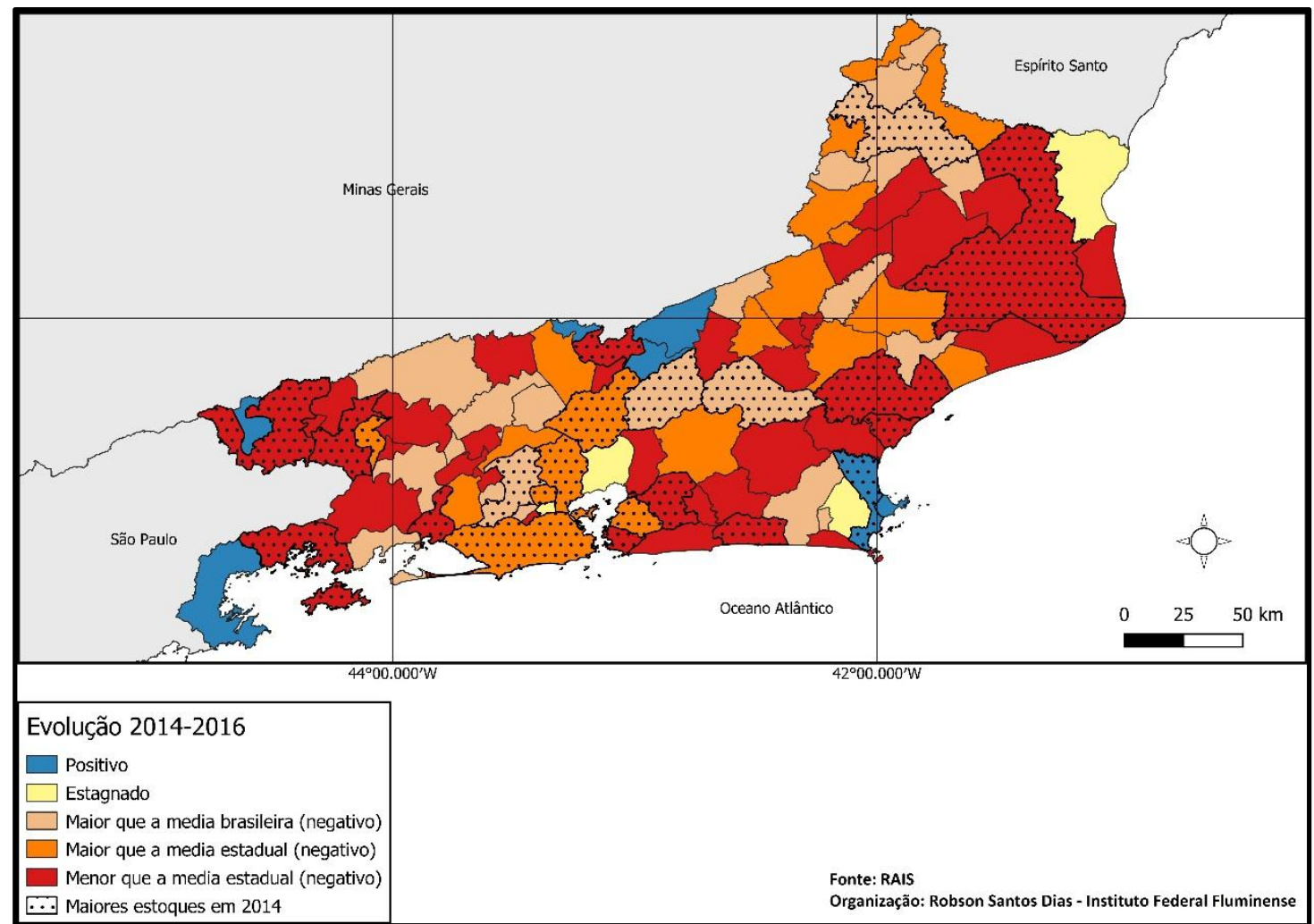

Fonte: RAIS (Relatório Anual Indicadores Sociais), MTE, http://pdet.mte.gov.br/microdados-rais-e-caged, anos 2014 - 2016, elaboração do autor (Instituto Federal Fluminense)

Entre 2016 e 2019 que, como visto, a nível nacional houve um estancamento e até alguma recomposição do emprego no agregado, o ERJ continuou a trajetória de perdas, em especial em virtude do decréscimo do estoque agregado metropolitano. No Figura 3 se observa que os principais estoques municipais na RMRJ apresentaram quedas superiores à média estadual, com exceção de Itaboraí e Maricá. Este município foi a grande novidade no período, visto que após a severa queda entre 2014 e 2016, o município apresentou vigorosa recuperação, superando o estoque de 20 mil empregos formais, entrando no rol aqui delimitado dos mercados de trabalhos municipais de maior porte. A contrapartida negativa foi

\footnotetext{
${ }^{26}$ Entre os profissionais da área de hospitalidade e lazer, diz-se que apesar da crise, os anos de 2015 e 2016 não foram ruins para alguns destinos indutores do turismo doméstico, já que muitos turistas trocaram destinos internacionais ou domésticos mais longínquos por destinos mais próximos de casa. Situado próximo aos principais mercados de consumo do país, verifica-se que os destinos de Cabo Frio-Búzios-Arraial do Cabo e de Paraty apresentaram crescimento no emprego nesse ínterim. É possível que a ocorrência da Olimpíada tenha também influenciado nesses casos.
} 
Saquarema, que viu reduzida enormemente seu estoque, de modo que de pouco mais 22 mil empregos em 2014, caiu para abaixo de 14 mil em 2019. Dentre os principais mercados do interior, os mais importantes, Macaé e Campos dos Goytacazes, assim como Angra dos Reis continuaram a apresentar perdas maiores que a média estadual. Teresópolis apresentou queda, porém em grau menos gravoso que a média estadual e Três Rios apresentou quadro de estagnação. Cabo Frio reverteu o bom resultado verificado até 2016, terminando em 2019 com perdas, ainda que menor que a média estadual. Por outro lado, os mercados de Resende, Volta Redonda, Barra Mansa, Nova Friburgo e Itaperuna conseguiram superar a média nacional. Vários municípios com estoques de emprego pequenos tiveram também expansão maior que a média brasileira, o que permite concluir que a continuidade da crise no mercado de trabalho formal fluminense tem sido um fenômeno mais específico dos municípios de maior estoque, tanto na RMRJ quanto no interior. Novamente, as vicissitudes que continuam a rondar os setores ligados à exploração de petróleo e gás, que vêm passando por acelerado processo de fragmentação privatista e consequente desnacionalização, tem tido papel central. Uma das consequências no ERJ é o descomissionamento de instalações produtivas na Bacia de Campos.

Figura 3 - Evolução do emprego formal entre 2016 e 2019

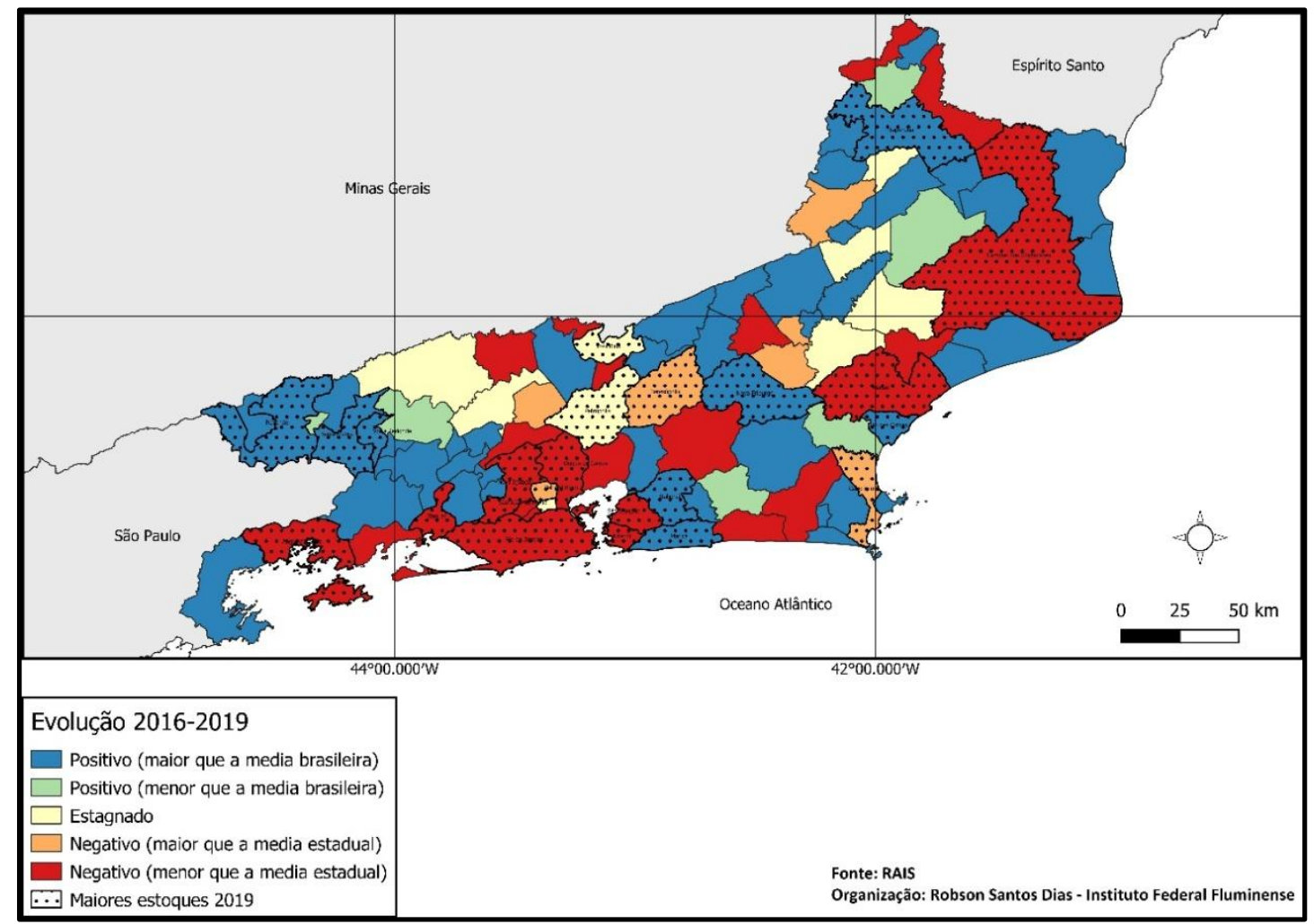

Fonte: RAIS (Relatório Anual Indicadores Sociais), MTE, http://pdet.mte.gov.br/microdados-rais-e-caged, anos 2016 - 2019, elaboração do autor (Instituto Federal Fluminense) 


\section{CONSIDERAÇÕES FINAIS}

A principal conclusão que se pode tirar da análise do mercado de trabalho formal fluminense é que desde 1985, seja nos ciclos de crise ou relativa estagnação da economia brasileira, seja nos ciclos de expansão, a economia fluminense, no tocante ao emprego, vem passando por sustentado processo de perda de participação relativa frente às demais unidades da federação. Como resultado, o ERJ vem sendo superado por outros estados, em especial da região Sul, em diversos indicadores, apesar de ainda figurar entre os estados com melhor relação emprego formal / população no Brasil. No que tange ao emprego, a "inflexão positiva" se limita à comparação do ERJ consigo mesmo, como aliás, a proposição original de Natal (2005) ponderava com rigor.

Setorialmente, o ERJ vem se especializando na indústria extrativa mineral e em atividades alavancada pela cadeia produtiva de petróleo e gás, que em si mesma, corresponde a uma parcela bastante reduzida do emprego formal. Todavia, a indústria extrativa mineral foi responsável pela contratação mais abundante de profissionais de nível salarial mais elevado, que apesar da perda relativa frente ao estoque estadual, ainda tem uma participação mais elevada no ERJ do que, por exemplo, em São Paulo. Outro destaque a ser dado é o fato de que a indústria de transformação fluminense vem perdendo pouco a pouco densidade e, portanto, participação no estoque de empregos fluminense. Há, no entanto, mediações sobre a evolução entre as diversas atividades industriais e sobre os lugares dessa evolução, tema que não foi aprofundado nesse estudo.

De maneira geral, o MRJ, dada sua macrocefalia, é o principal responsável pelo perfil retardatário do mercado de trabalho formal fluminense. Tanto o interior, quanto parte dos demais municípios metropolitanos, em geral, apresentaram uma evolução mais acelerada dos níveis de emprego. Não se deve, no entanto, superestimar tal fenômeno. A força gravitacional do MRJ na economia fluminense é imensa, e por mais que seja bem-vinda a desconcentração do emprego no estado, uma capital economicamente fragilizada fatalmente enfraquece o interior fluminense, tendo em vista a capacidade de polarização do MRJ. O crescimento do interior, por outro lado, foi concentrado em alguns poucos municípios, seja do ponto de vista do crescimento percentual, seja do ponto de vista da sua participação no saldo positivo alcançado ao longo do período (com exceção de 2015 em diante). E esses municípios estão na sua quase totalidade, ligados ao MRJ por meio de eixos rodoviários de fácil acesso, articulando os municípios dinâmicos ou de mercado de trabalho de maior porte ao espaço metropolitano. 
A crise a partir de 2015 inicialmente causou estragos em quase todos os municípios fluminenses, mas foi principalmente naqueles que se destacaram na expansão entre 2000 e 2014 que o impacto foi mais profundo. No caso, os municípios que colheram frutos com o os encadeamentos econômicos da extração de petróleo e gás natural apresentaram perdas severas no auge da crise (2015 e 2016) e continuaram a apresentar taxas negativas entre 2016 e 2019, quando o agregado brasileiro e mesmo alguns municípios fluminenses conseguiram estancar as perdas e até ensaiar uma pequena recuperação dos estoques de emprego.

Ao que tudo indica, o retorno do ERJ para um novo ciclo expansivo depende de uma série de fatores endógenos e exógenos. A capacidade de articulação política, econômica e institucional dos fluminenses continua sendo um fator deveras fundamental para se construir novas perspectivas para o estado. Investimentos em políticas sociais, de desenvolvimento de capacidades tecnológicas e melhorias de infraestrutura são essenciais. Entretanto, não suficientes, pois como vimos, o ERJ continua dependendo fundamentalmente de como caminha o Brasil. Tudo indica que o estado continuará dependente do segmento petrolífero, haja vista a localização do pré-sal situar-se, em grande parte, no litoral sul fluminense. Mas o aproveitamento desse potencial depende antes de tudo do estado da política em Brasília. $\mathrm{O}$ que será feito desse recurso? Voltaremos a ter políticas de conteúdo local mais robustas? O Estado, em sua complexa escalaridade, deixará de ser demonizado como importante indutor de crescimento econômico? Voltaremos a ter política industrial consistente?

São questões que interessam a todos os brasileiros, evidentemente. Mas em especial aos fluminenses.

\section{REFERÊNCIAS}

DAIN, S. Rio de todas as crises: crise econômica. Série estudos e pesquisas, n. 80, IUPERJ, dezembro 1990, p. 1-8.

DAVIDOVICH, F. Metrópole e território: metropolização do espaço no Rio de Janeiro. Cadernos Metrópole. São Paulo, n. 6, 2001, p. 67-77.

Estado do Rio de Janeiro: o urbano metropolitano. Hipóteses e questões. GeoUERJ. Rio de Janeiro, n. 21, v. 2, 2010. 
DIAS, R. S. Vida e morte da questão regional na agenda governamental do Estado do Rio de Janeiro pós-fusão: o caso da FUNDREM. Tese de doutorado. Rio de Janeiro: Instituto de Pós-Graduação e Pesquisa em Planejamento Urbano e Regional - UFRJ, 2015.

FIEGA. A fusão dos estados da Guanabara e do Rio de Janeiro. Rio de Janeiro: Mimeo, 1969.

HASENCLEVER, L. MENDES, H. CAVALIERE, H. Especialización en recursos naturales y empleo en Brasil: El caso del petróleo en Río de Janeiro. Red Sud Americana de Economía Aplicada, Serie Documentos de Base del Reporte Recursos Naturales y Desarrollo 2015-2016, estudio país n. 3. Disponível em: https://obpetro.com.br/wpcontent/uploads/2020/07/EP-3.-Especializacion-en-RRNN-y-empleo-en-Brasil-el-caso-delPetroleo-en-ERJ.pdf. Acesso em: 05 abr. 2021.

LENCIONI, S. Urbanização difusa e a constituição de megarregiões. O caso de São PauloRio de Janeiro. E-metrópolis. Rio de Janeiro, n. 22, 2015, p. 6-15.

MORAES, A. M; SANTOS, L. B. Indústria e organização espacial: lógicas locacionais dos investimentos na indústria de transformação no estado do Rio de Janeiro (2006-2016). Espaço e economia. Rio de Janeiro, n. 15, 2019.

NATAL, J. O Estado do Rio de Janeiro Pós 95: dinâmica Econômica, rede urbana e questão social. Rio de Janeiro: Publicatti, 2005.

OLIVEIRA, F. J. G. Reestruturação produtiva, território e poder no Estado do Rio de Janeiro. Tese de doutorado. São Paulo: Programa de Pós-Graduação em Geografia Humana - USP, 2003.

OLIVEIRA, L. D. A emersão da região logístico-industrial do Extremo Oeste Metropolitano Fluminense: reflexões sobre o processo contemporaneo de reestruturação territorialprodutiva. Espaco e economia. Rio de Janeiro, n. 7, 2015.

OSORIO, M. Estado do Rio de Janeiro: estagnação e rumos de reversão. Jornal dos economistas. Rio de Janeiro: CORECON-RJ, n. 224, 2008, p. 3-5.

PESSANHA, R. M. A ampliação da fronteira de exploração petrolífera no Brasil é parte da geopolítica da energia: oportunidades e riscos de inserção global em meio às novas territorialidades regionais e ao desafio da abundância na economia dos royalties no Estado do Rio de Janeiro. Espaço e economia. Rio de Janeiro, n. 6, 2015. 
SANTOS, A. M. P. Economia, espaço e sociedade no Rio de Janeiro. Rio de Janeiro: FGV Editora, 2003.

SILVA, R. D. Rio de Janeiro: crescimento, transformações e sua importância para a economia nacional. Dissertação de mestrado. Campinas: Instituto de Economia - Unicamp, 2004

Indústria e desenvolvimento regional no Rio de Janeiro. Rio de Janeiro: FGV Editora, 2012.

SOBRAL, B. L. B. A falácia da "inflexão econômica positiva": algumas características da desindustrialização fluminense e do "vazio produtivo" em sua periferia metropolitana. Cadernos do desenvolvimento fluminense. Rio de Janeiro, n. 1, 2013, p. 53-85. 